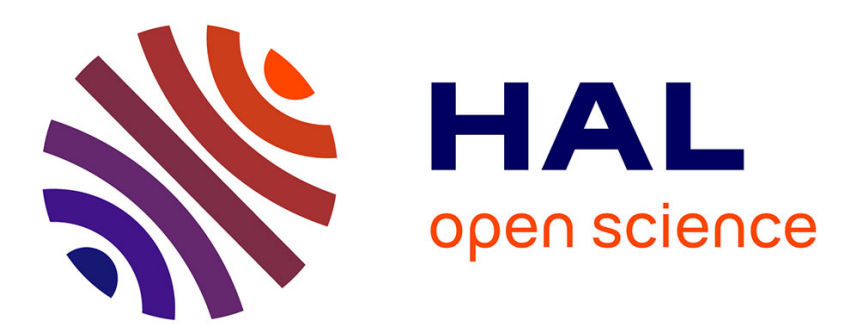

\title{
Numerical Study of Jet-Target Interaction: Influence of Dielectric Permittivity on the Electric Field Experienced by the Target
}

\author{
Pedro Viegas, Anne Bourdon
}

\section{- To cite this version:}

Pedro Viegas, Anne Bourdon. Numerical Study of Jet-Target Interaction: Influence of Dielectric Permittivity on the Electric Field Experienced by the Target. Plasma Chemistry and Plasma Processing, 2020, 40, pp.661-683. 10.1007/s11090-019-10033-6 . hal-02342270

\author{
HAL Id: hal-02342270 \\ https://hal.science/hal-02342270
}

Submitted on 14 Jul 2020

HAL is a multi-disciplinary open access archive for the deposit and dissemination of scientific research documents, whether they are published or not. The documents may come from teaching and research institutions in France or abroad, or from public or private research centers.
L'archive ouverte pluridisciplinaire HAL, est destinée au dépôt et à la diffusion de documents scientifiques de niveau recherche, publiés ou non, émanant des établissements d'enseignement et de recherche français ou étrangers, des laboratoires publics ou privés. 


\title{
Numerical study of jet-target interaction: influence of dielectric permittivity on the electric field experienced by the target
}

\author{
Pedro Viegas $¥$ and Anne Bourdon ${ }^{1}$ \\ ${ }^{1}$ LPP, CNRS, École Polytechnique, Sorbonne Université, Université Paris-Sud, \\ Université Paris-Saclay, 91128 Palaiseau, France \\ E-mail: p.viegas@differ.nl; anne.bourdon@lpp.polytechnique.fr
}

13 September 2019

\begin{abstract}
.
This work presents a study of the influence of dielectric permittivity on the interaction between a positive pulsed He plasma jet and a $0.5 \mathrm{~mm}$-thick dielectric target, using a validated two-dimensional numerical model. Six different targets are studied: five targets at floating potential with relative permittivities $\epsilon_{r}=1,4,20$, 56 and 80; and one grounded target of permittivity $\epsilon_{r}=56$. The temporal evolution of the charging of the target and of the electric field inside the target are described, during the pulse of applied voltage and after its fall. It is found that the order of magnitude of the electric field inside the dielectric targets is the same for all floating targets with $\epsilon_{r} \geq 4$. For all these targets, during the pulse of applied voltage, the electric field perpendicular to the target and averaged through the target thickness, at the point of discharge impact, is between 1 and $5 \mathrm{kV} \cdot \mathrm{cm}^{-1}$. For the two remaining targets $\left(\epsilon_{r}=1\right.$ and grounded target with $\left.\epsilon_{r}=56\right)$, the field is significantly higher than for all the other floating targets.
\end{abstract}

PACS numbers:

Keywords: plasma target interaction, plasma dielectric interaction, plasma jet, electric field, surface charges.

\section{Introduction}

Due to emerging applications, non-thermal atmospheric pressure plasma jets have attracted a lot of attention in the past 20 years. Several groups have studied plasma jets experimentally and numerically, and several reviews on jets have been published in the last years Schutze et al. 1998; Laimer and Stori, 2007, Laroussi and Akan, 2007; Lu et al., 2012, 2014, Winter et al., 2015a. Jets have the ability to deliver in remote locations a wide range of reactive species ( $\mathrm{NO}, \mathrm{OH}, \mathrm{NO}_{2}, \mathrm{H}_{2} \mathrm{O}_{2}, \mathrm{O}, \mathrm{O}_{3}$ ),

$\ddagger$ Present address: DIFFER - Dutch Institute for Fundamental Energy Research, 5612 AJ Eindhoven, The Netherlands 
charged species, high electric fields and UV photons. Thus, they are very promising devices for applications in the areas of material science and biomedicine. These are highlighted in several papers and reviews Fridman et al., 2008; Kong et al., 2009; Collet et al., 2014; Graves, 2015; Laroussi, 2015; Weltmann and von Woedtke, 2017; Reuter et al., 2018 and include decontamination, microbial sterilization, cancer treatment, coagulation, wound healing, dental treatment, surface functionalization and treatment for agriculture. Among the applications, we would like to highlight the role of the electric field in the discharge when applied on living tissues. In some applications where the jet is used to destroy (or cause the apoptosis of) diseased cells, the electric field produces the electroporation of the cells, which allows for reactive species or even therapeutic drugs to be successfully introduced into the cells Kim et al., 2010; Mirpour et al. 2014; Zhang et al., 2014. Most of the targets in these applications, such as organic materials and polymers, have a dielectric character. Therefore, a proper understanding of discharge-dielectric interaction is essential for the optimization of jet applications.

The interaction of jets with dielectric surfaces of different permittivities has been addressed in several experimental and numerical works Breden and Raja, 2014, Norberg et al., 2015; Wang et al., 2016; Yan and Economou, 2016; Ning et al., 2018; Klarenaar et al., 2018; Ji et al., 2018; Lazarou et al., 2018; Yue et al., 2018; Zheng et al., 2018; Hofmans and Sobota, 2019; Sobota et al., 2019; Schweigert et al., 2019; Babaeva et al., 2019. In Norberg et al. 2015 it has been studied numerically in 2D the impact of He jets on dielectric and metallic grounded targets with a $-15 \mathrm{kV}$ voltage pulse. The propagation of the ionization waves has been described as being slightly faster towards targets of higher permittivity, followed by the impact and spreading on the target surface in the case of dielectric targets of different permittivities, along with the resulting electric field distribution inside the target. Furthermore, the differences between the different targets have been reported, along with their impact on species production in the plasma plume. With low values of $\epsilon_{r}$, up to 10 , the target has lower capacitance and a shorter $\mathrm{RC}$ time constant for charging the surface, which quickly leads to the depletion of the axial component of electric field and the rise of the radial component that sustains the propagation of the discharge on the surface. With high values of $\epsilon_{r}$, such as 80 for liquids, and with metallic targets, the charging of the surface is slower or inexistent, there is low radial component of electric field and no or little discharge propagation on the surface. Wang et al. 2016 have also studied numerically the interaction of He jets with dielectric surfaces of different permittivity $\left(\epsilon_{r}=2,5,10\right)$, but with positive polarity of applied voltage. In agreement with Norberg et al. [2015, they have shown that the lower impedance of the dielectric with higher $\epsilon_{r}$ enhances the electric field in the plasma column, leading to an increase of the electron density in the plasma column. Moreover, in that work the surface charge density on the target surface has been shown to be proportional to $\epsilon_{r}$, while the radial component of electric field while the discharge is spreading on the target surface is inversely proportional to $\epsilon_{r}$. Then, in Klarenaar et al. 2018 the electron densities and temperatures have been experimentally obtained through Thomson scattering with spatial and temporal resolution in a He jet freely 
expanding or interacting with floating targets of different electrical properties. The same macroscopic behaviors reported in Norberg et al. 2015 have been observed and their effect on the electron properties have been reported, with electron density close to the target reaching three times higher values with a metallic target than a glass target. Other experimental and numerical works Ji et al., 2018; Yue et al., 2018; Sobota et al. 2019 have found the same tendencies as in Norberg et al. 2015, in terms of influence of the target on discharge velocity, radial spreading on the target and electric field in the front of propagation.

Experimentally, some investigations have focused on the examination of electric fields inside dielectric targets exposed to discharge impact. These can be investigated with Mueller polarimetry using electro-optic crystals, since their refractive index changes linearly with the induced electric field. The electric field components can be obtained with temporal resolution and along the surface of the crystal, but not along its thickness. Thus, it is considered as the field averaged through the crystal thickness. The visualization of electric field using electro-optic materials has been applied by Kawasaki et al. [1991]; Zhu et al. [1995] to study the propagation of streamers on dielectrics. It has also been used with He plasma jets by Sobota et al. [2013]; Wild et al. [2014]; Slikboer et al. 2016, 2017, 2018 and DBDs by Stollenwerk et al. 2007]; Bogaczyk et al. 2012]; Tschiersch et al. [2014]. It offers an unique way to estimate the fields these targets are exposed to and to also investigate the dynamics of the discharge propagation on the target surface. In plasma simulations, the electric field can be calculated at each point of a computational domain at each time-step. Thus, the recent developments in electric field measurements in He plasma jets in experiments, together with plasma simulations, provide an excellent opportunity for detailed characterization of He jets and their applications on targets.

Recently, in Viegas et al., 2018b, a qualitative comparison between experiments and simulations has provided explanation for the difference between the rather high values of electric field measured in the jet plume and the rather low values measured inside a dielectric target. The experiments have used a BSO target of relative permittivity $\epsilon_{r}=56$ and the simulations a glass target of $\epsilon_{r}=4$. Furthermore, that work has allowed to describe the discharge dynamics and relate it with the electric field distributions. Then, in Slikboer et al. [2019], quantitative comparisons of temporally and spatially resolved electric field evolutions have been performed, considering the same conditions in experiments and simulations and the BSO target. The simulation results have been averaged over $25 \mathrm{~ns}$ and through the target thickness to be compared with experimental measurements with the same temporal and spatial resolution. That work has investigated the dynamical charging of a surface under exposure of a positive pulsed plasma jet and an excellent agreement between experimental and numerical results has been obtained. It has been shown with variable pulse duration and amplitude that the charging time (i.e. the time from the impact of the ionization wave until the fall of the high voltage pulse) is a crucial element to determine the spreading of the discharge and the charge deposition on the surface and thus the electric field the target is exposed 
to. Both works have used the BSO target in the experiments, due to its electro-optic properties, necessary for the diagnostic. Yet, discharge dynamics can vary significantly when interacting with different surfaces. Plasma simulations are less constrained in terms of target permittivity, as $\epsilon_{r}$ can be easily changed.

In this work, we investigate through numerical simulations the influence of the target permittivity specifically on the electric field experienced by the target. Moreover, we evaluate if the electric field measured inside the BSO target is representative of the electric field inside other dielectric targets, under impact of positive pulsed jets. In addition to different permittivities of targets at floating potential, a grounded BSO target is also studied. In section 2 the two-dimensional axisymmetric fluid model is described. Then, in section 3.1 the discharge dynamics interacting with the different targets is described and in section 3.2 the comparison between targets is focused on the charging of the target surface and on the electric field inside the target. Finally, an appendix presents a short study of the sensitivity of the results to the reaction scheme in use in the model.

\section{Numerical model}

The model set-up is shown in Figure 1. The geometry taken is the same as in the experiments in Slikboer et al. [2019]. A dielectric quartz tube with relative permittivity of $\epsilon_{r}=4$, length $3.3 \mathrm{~cm}$ (between $z=1.0 \mathrm{~cm}$ and $z=4.3 \mathrm{~cm}$ ), internal radius $r_{\text {in }}=1.25 \mathrm{~mm}$ and outer radius $r_{\text {out }}=2.0 \mathrm{~mm}$ is used. Also, a dielectric target is placed perpendicularly to the tube at $1 \mathrm{~cm}$ from the end of the tube. The target is defined as a cylinder of $2 \mathrm{~cm}$ radius and $0.5 \mathrm{~mm}$ thickness, set between $z=-0.5 \mathrm{~mm}$ and $z=0$. In this work, targets of different relative permittivities are used: 1,4 , 20, 56 and 80. $\epsilon_{r}=1$ corresponds to the limit case in which there is no change of permittivity with respect to the gas. $\epsilon_{r}=4$ is the value used in the model in Viegas et al. 2018b and approximately corresponds to organic polymers, biological tissues and materials such as glass. In Slikboer et al. [2019] a BSO target of $\epsilon_{r}=56$ has been used in the model, to match the electric field measurements with the same target. We should notice that the numerical description of the plasma-target interaction with this target has been validated through comparisons with experiments in that publication. $\epsilon_{r}=20$ represents a target of intermediate permittivity, between the latter two. Finally, $\epsilon_{r}=80$ is approximately the permittivity of liquid targets, which in many cases surround biological tissues. The targets are at a floating potential as in the experiments, and a grounded plane is set $10 \mathrm{~cm}$ behind it. One additional target configuration has been used, with $\epsilon_{r}=56$ but grounded, i.e. with the grounded plane at $z=-0.5 \mathrm{~mm}$. A powered ring electrode of inner radius $0.4 \mathrm{~mm}$ and outer radius $1.25 \mathrm{~mm}$ is set inside the tube between $z=3.8 \mathrm{~cm}$ and $z=4.3 \mathrm{~cm}$ and a grounded ring is wrapped around the glass tube between $z=3.0 \mathrm{~cm}$ and $z=3.3 \mathrm{~cm}$, at a distance of $0.5 \mathrm{~cm}$ from the inner ring. As in experiments, the inner ring is powered by an applied voltage that rises during $50 \mathrm{~ns}$ until reaching $V_{P}=6 \mathrm{kV}$. In the experiments SSlikboer et al., 2019 the pulse width 
is variable and the frequency of pulse repetition is $5 \mathrm{kHz}$. In this work, the voltage is constant until $t=600 \mathrm{~ns}$ and decreases from there until $t=650 \mathrm{~ns}$, when it reaches zero. Taking into account the high repetition rate in experiments, we consider that relatively high densities of electrons and positive ions remain in the discharge domain between pulses, as is also argued in Naidis [2011]. Given the uncertainty on what the exact initial conditions should be to reproduce the repetitive discharges, we take into account a standard uniform initial preionization density $n_{\text {init }}=10^{9} \mathrm{~cm}^{-3}$ of electrons and $\mathrm{O}_{2}^{+}$. However, no initial surface charges are considered on the dielectric surfaces.

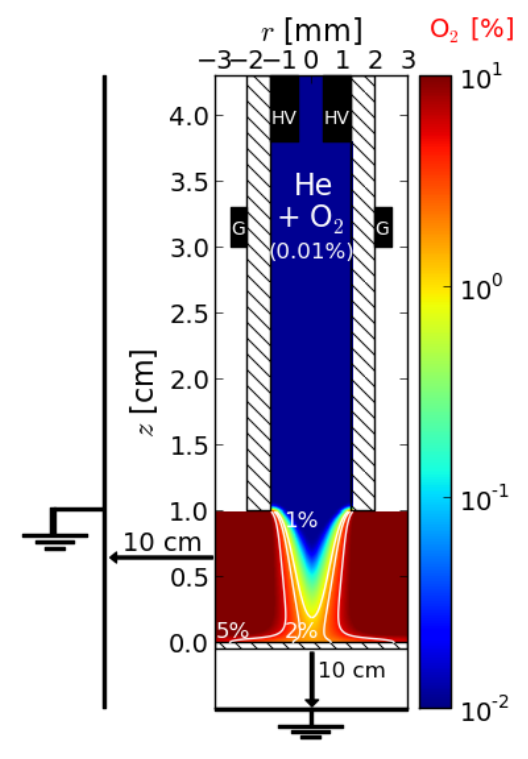

Figure 1. Side view schematics of the discharge set-up used in the simulations. The colour plot and the white curves show the $\mathrm{O}_{2}$ spatial distribution in the $\mathrm{He}-\mathrm{O}_{2}$ mixture (percentage over a total of $2.45 \times 10^{19} \mathrm{~cm}^{-3}$ gas density).

Figure 1 also shows that the discharge set-up is placed inside a grounded cylinder with a radius of $10 \mathrm{~cm}$. Between the dielectric target and the grounded plane, as well as between the dielectric tube and the grounded cylinder, the space is considered as a dielectric of air permittivity $\epsilon_{r}=1$. On the last boundary of the domain (i.e. at $z=4.8$ $\mathrm{cm}$ ), the axial gradient of electric potential is set to zero. The computational domain is cylindrically symmetrical and the simulations have been carried out at atmospheric pressure and at $T=300 \mathrm{~K}$. To simulate the discharge dynamics, we use as in Viegas et al. 2018b]; Slikboer et al. 2019] a 2D axisymmetric fluid model based on drift-diffusionreaction equations for electrons, positive ions and negative ions and reaction equations for neutral species, coupled with Poisson's equation in cylindrical coordinates $(z, r)$ :

$$
\begin{aligned}
& \frac{\partial n_{i}}{\partial t}+\nabla \cdot \mathbf{j}_{\mathbf{i}}=S_{i} \\
& \mathbf{j}_{\mathbf{i}}=\left(q_{i} /|e|\right) n_{i} \mu_{i} \mathbf{E}-D_{i} \nabla n_{i} \\
& \epsilon_{0} \nabla \cdot\left(\epsilon_{r} \nabla V\right)=-\rho-\sigma \delta_{s} \\
& \mathbf{E}=-\nabla V ; \rho=\sum q_{i} n_{i}
\end{aligned}
$$


where the subscript $i$ refers to each species and $n_{i}, q_{i}, j_{i}, \mu_{i}$ and $D_{i}$ are the number density, the charge, the flux, the mobility and the diffusion coefficient of each species $i$, respectively. $S_{i}$ is the total rate of production and destruction of species $i$ by kinetic processes and by photoionization. $V$ is the electric potential, $\mathbf{E}$ the electric field, $e$ the electron charge, $\epsilon_{0}$ the vacuum permittivity, $\epsilon_{r}$ the relative permittivity and $\delta_{s}$ the Kronecker delta (equal to 1 on the dielectric/gas interfaces). In this work, as in Slikboer et al. [2019], the description of electron energy is included to be able to describe the plasma with the grounded ring around the tube and targets with high permittivity. The inclusion of the grounded ring around the tube is important to describe the ignition and propagation of the discharge. In Viegas 2018] (chapter III.3) it has been shown that the inclusion of the grounded ring around the tube, placed between the powered electrode and the target, leads to faster discharge ignition and propagation and to a significant charging of the tube inner surface. The description of the electron energy in the model is obtained by implementing the electron energy conservation equation. By adopting the same approximations as in Alves et al. [2018]; Hagelaar and Pitchford [2005], the equation is written:

$$
\begin{aligned}
& \frac{\partial}{\partial t}\left(n_{e} \epsilon_{m}\right)+\nabla \cdot \mathbf{j}_{\epsilon}=-\left|q_{e}\right| \mathbf{E} . \mathbf{j}_{\mathbf{e}}-\Theta_{e} \\
& \mathbf{j}_{\epsilon}=-n_{e} \epsilon_{m} \mu_{\epsilon} \mathbf{E}-D_{\epsilon} \nabla\left(n_{e} \epsilon_{m}\right)
\end{aligned}
$$

where $n_{\epsilon}=n_{e} \epsilon_{m}$ is the electron energy density, defined by the multiplication between the electron density and the electron mean energy, $\Theta_{e}$ represents the power lost by electrons in collisions and $j_{\epsilon}$ is the flux of $n_{\epsilon}$ by drift and diffusion. Thus, eq. (5) takes the same form of the continuity equations for charged species with drift-diffusion approximation.

It is important to point out that at the surface of both the tube and the target, secondary emission of electrons by ion bombardment ( $\gamma=0.1$ for all ions) is taken into account. The surface charge density $\sigma$ on the surface of the dielectrics is obtained by time-integrating charged particle fluxes through electric drift to the surface. We consider that these charges then remain immobile on the surface of the dielectrics. The plasma model has been coupled with static flow calculations Viegas et al., 2018b; Viegas, 2018. In the experiments Slikboer et al. 2019], 1 slm of He with some air impurities flows through the tube into air. As a first approximation, the model considers a flow of $1 \mathrm{slm}$ of helium with 100 ppm of $\mathrm{O}_{2}$ impurities flowing downstream into an $\mathrm{O}_{2}$ environment. Both experiments and simulations Winter et al., 2015b; Schmidt-Bleker et al., 2015] have shown that the use of $\mathrm{O}_{2}$ or air as surrounding gas for a He jet present similarities with respect to discharge dynamics in the plasma plume. In Naidis [2011]; SchmidtBleker et al. [2015] the important role of the electronegativity of the surrounding gas, either $\mathrm{O}_{2}$ or air, has been highlighted. Finally, in Viegas 2018] (chapter III and appendix $\mathrm{F}$ ), attachment in oxygen has been shown to be relevant for the radial confinement of the discharge in the plume. Moreover, in that work the influence of $\mathrm{O}_{2}$ impurities in the He flow, up to $1 \%$, has been studied and it has been shown to have little relevance on the dynamics of propagation of the discharge. The spatial distribution of $\mathrm{O}_{2}$ in the $\mathrm{He}-\mathrm{O}_{2}$ mixture obtained from the flow calculation is presented in Figure 1. 
In Viegas et al. [2018a, b], the reaction scheme proposed in Liu et al. [2010] has been used to describe the kinetics in the He- $\mathrm{O}_{2}$ plasma. The scheme includes a total of 288 reactions with 5 positive ions, 5 negative species and 11 neutral species. In this work a reduced reaction scheme is used. The reduction consists on keeping only the 10 most important species in the $\mu$ s timescales under study: e, $\mathrm{O}_{2}^{-}, \mathrm{He}^{+}, \mathrm{He}_{2}^{+}, \mathrm{O}_{2}^{+}$, $\mathrm{He}, \mathrm{He}\left(2^{3} \mathrm{~S}, 2^{1} \mathrm{~S}\right), \mathrm{O}, \mathrm{O}_{2}, \mathrm{O}_{2}\left(a_{1} \Delta_{g}\right)$. By excluding the reactions concerning the other 11 species, the scheme is reduced to 55 reactions. In tables 2 and 3 in the appendix, the list of reactions and rate coefficients used in the reduced reaction scheme is used. It has been verified that the discharge dynamics of propagation and thus the time of impact on the target and the radius of the discharge are not affected by the scheme reduction. In the appendix, it is shown that the surface charge deposition on the dielectric target and the values of electric field inside the target are affected in less than $10 \%$ by the scheme reduction for the cases of floating targets with $\epsilon_{r}=4$ and 56 . As a result of the chemistry reduction, the calculation time is reduced approximately by a factor 2.5 . The electron and electron energy transport parameters and the rate coefficients of electronimpact reactions are calculated with the electron Boltzmann equation solver BOLSIG+ Hagelaar and Pitchford, 2005, using the IST-Lisbon database of cross sections in LXCat Pancheshnyi et al., 2012, IST, 2018], and tabulated as functions of both the local gas mixture and the local mean electron energy $\epsilon_{m}$. In each cell and at each timestep, each coefficient $k$ is calculated for the local values of mixture and $\epsilon_{m}$ by linear interpolation between the upper and lower tabulated values and we obtain $k\left(\epsilon_{m}, m i x\right)$, as in Viegas [2018. For the photoionization model, we use the approach described in Bourdon et al. [2016]; Slikboer et al. [2019]. The ionizing radiation is assumed to be proportional to the excitation rate of helium atoms by impact of electrons. Then, the photoionization source term is proportional to the amount of $\mathrm{O}_{2}$ and thus we use as proportionality $A_{p h}=100 \times X_{\mathrm{O}_{2}}$. In the studied conditons, photoionization plays a key role in the discharge propagation from the end of the tube towards the targets. The role of photoionization on discharge propagation has been evaluated in Viegas [2018] (chapter III).

A finite volume approach and a cartesian mesh are used. The mesh size is $10 \mu \mathrm{m}$ axially between $z=-0.05 \mathrm{~cm}$ and $z=4.3 \mathrm{~cm}$ and radially between $r=0$ and $r=4.0$ $\mathrm{mm}$. Then, both behind the target and for $r>4.0 \mathrm{~mm}$, the mesh size is expanded using a geometric progression. The refinement taken requires a mesh of $\mathrm{n}_{z} \times \mathrm{n}_{r}=$ $4400 \times 470=2.068$ million points. The average computational time required for a 2 $\mu$ s simulation run to obtain the results presented in this paper was of three days with 64 MPI processes on a multicore cluster "Hopper" (32 nodes DELL C6200 bi-pro with two 8-core processors, 64 Go of memory and $2.6 \mathrm{GHz}$ frequency per node). Further details on the numerical schemes and other characteristics of the simulations are given in Viegas 2018. 


\section{Results}

\subsection{Influence of target permittivity on discharge dynamics}

In every case considered, the discharge ignites inside the tube, near the powered electrode, and propagates towards the end of the tube and then towards the target. Table 1 presents the time of impact of the discharge on the targets at floating potential for each case and for grounded target with $\epsilon_{r}=56$. The time of impact is defined as the instant when the maximum of the axial component of electric field is the closest to the surface of the target, with a 10 ns resolution.

\begin{tabular}{|c|c|}
\hline Target & Impact time $[\mathrm{ns}]$ \\
\hline$\epsilon_{r}=1$ & 340 \\
$\epsilon_{r}=4$ & 330 \\
$\epsilon_{r}=20,56,80$ & 320 \\
$\epsilon_{r}=56$, grounded & 270 \\
\hline
\end{tabular}

Table 1. Time of impact of the discharge on the different targets.

It is shown in table 1 that the time of impact, and thus the velocity of discharge propagation, are only slightly affected by the target permittivity in the case of floating targets. However, the propagation with $\epsilon_{r}=56$ and grounded target is significantly faster than the one towards floating target, with impact $50 \mathrm{~ns}$ earlier. The same trends have been reported by the experiments and simulations in Ji et al. 2018. Then, Fig. 2 shows the spatial distribution of electron density in the plasma plume, between the tube and the target, for three cases of floating target: low $\epsilon_{r}=4$, intermediate $\epsilon_{r}=20$ and high $\epsilon_{r}=80$. Four stages of discharge-target interaction are presented: discharge propagating between the tube and the target at $t=300 \mathrm{~ns}$, discharge front impacting the target surface, radial spreading approximately $100 \mathrm{~ns}$ after the impact and immediately before the fall of the applied voltage, at $t=600 \mathrm{~ns}$.

The results in Fig. 2 at $t=300$ ns confirm that $\epsilon_{r}$ does not significantly change the velocity of discharge propagation and the values of electron density during propagation. Then, when the discharge front is very close to the target surface, in the last $2 \mathrm{~mm}$ of propagation, the electric field in the front and its velocity of propagation increase with $\epsilon_{r}$, justifying the 20 ns difference in time of impact between the case with $\epsilon_{r}=1$ and $\epsilon_{r}=80$. As a result, also the electron density very close to the surface increases with $\epsilon_{r}$. A difference between different targets of electron density and peak electric field only very close to the surface has also been measured in Klarenaar et al. 2018; ; Sobota et al. 2019] and simulated in Ji et al. 2018; Schweigert et al. 2019. Then, after the discharge hits the target, positive charge deposition takes place on the surface and the discharge spreads radially outwards. Finally, we notice that between the impact on the surface and the end of the pulse, the radial spreading of the discharge is significantly faster for lower $\epsilon_{r}$. In fact, it is shown that at $t=600 \mathrm{~ns}$ the discharge front has reached $r=3.5 \mathrm{~mm}$ with $\epsilon_{r}=4$, but only $r=2.5 \mathrm{~mm}$ with $\epsilon_{r}=20$ and $r=1.5 \mathrm{~mm}$ with 


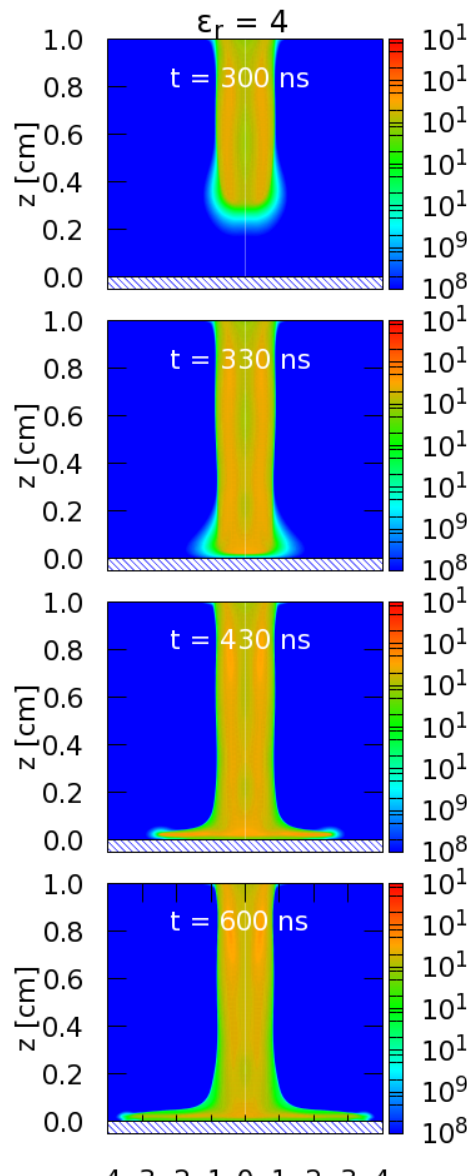

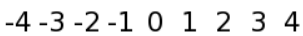
$\mathrm{r}[\mathrm{mm}]$
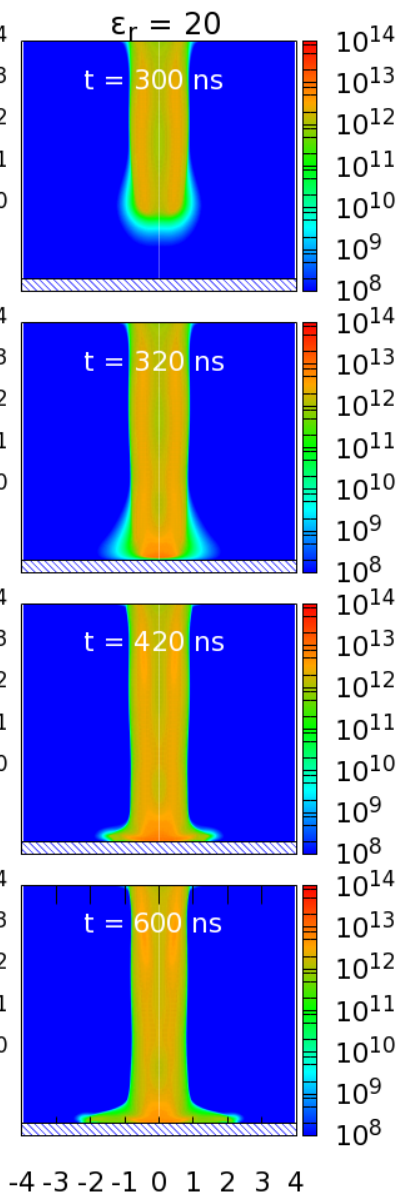

$\mathrm{r}[\mathrm{mm}]$
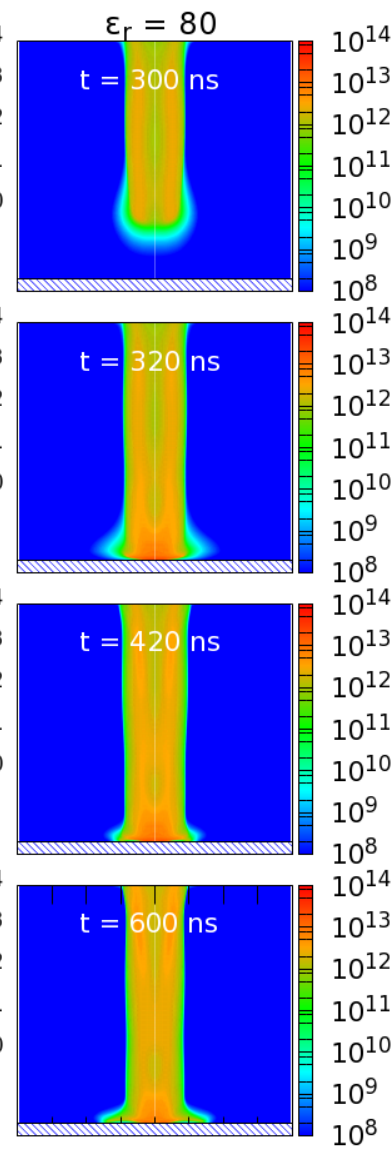

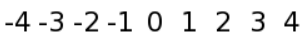

$\mathrm{r}[\mathrm{mm}]$

Figure 2. Cross section of spatial distribution of electron density in the plasma plume. From left to right: $\epsilon_{r}=4,20$ and 80. From top to bottom: discharge propagation in the plasma plume, discharge impact, radial spreading $100 \mathrm{~ns}$ after impact and immediately before end of pulse.

$\epsilon_{r}=80$. These results agree with those reported in other numerical and experimental works Norberg et al., 2015; Wang et al., 2016; Yue et al., 2018; Klarenaar et al., 2018. Then, in Fig. 3, the spatial distribution of other species is presented at $t=600 \mathrm{~ns}$. The main negative and positive ions $\mathrm{O}_{2}^{-}$and $\mathrm{O}_{2}^{+}$are shown, together with two excited metastable species of different elements, $\mathrm{He}^{*}$ and $\mathrm{O}_{2}(\mathrm{a})$.

The distributions of $\mathrm{O}_{2}^{-}$and $\mathrm{O}_{2}^{+}$presented in Fig. 3 show densities in the region without plasma with approximately the same value as the preionization density $10^{9}$ $\mathrm{cm}^{-3}$. In fact, in that region the electrons from preionization are quickly attached. Then, as the ion-ion recombination is rather slow (rate $\sim 5 \times 10^{12} \mathrm{~cm}^{-3} \cdot \mathrm{s}^{-1}$ in these conditions), $\mathrm{O}_{2}^{-}$and $\mathrm{O}_{2}^{+}$remain in the region without plasma during the timescales of discharge propagation. In the plasma region, we see that the negative ion density is significantly lower than the electron density and that the density of $\mathrm{O}_{2}^{+}$is approximately the same as that of electrons, thus being the dominant ion. It is also clear in Fig. 3 the dependence of $\mathrm{He}^{*}, \mathrm{O}_{2}^{-}$and $\mathrm{O}_{2}(\mathrm{a})$ on the $\mathrm{He}-\mathrm{O}_{2}$ mixture. $\mathrm{He}^{*}$ is only present in 


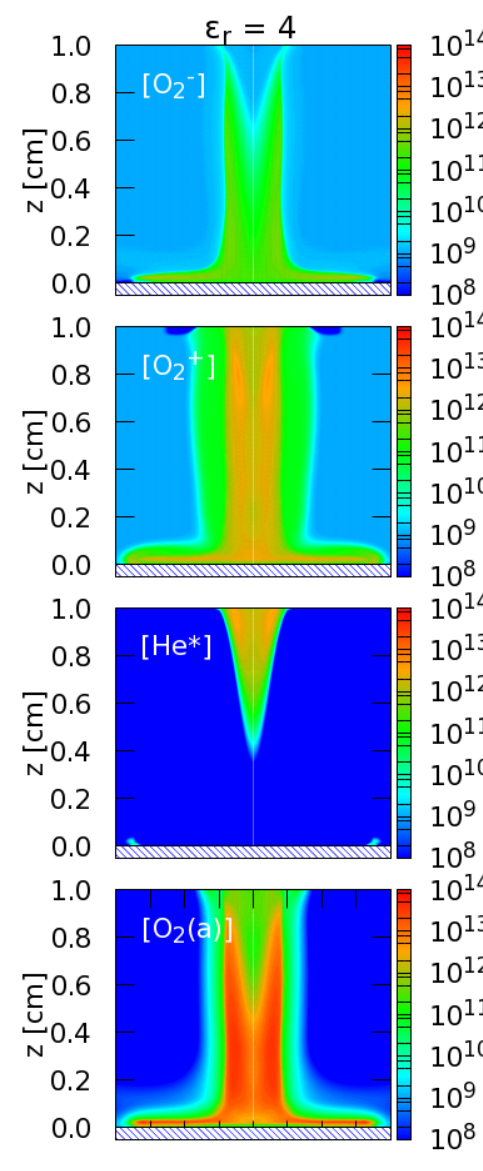

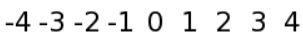
$\mathrm{r}[\mathrm{mm}]$
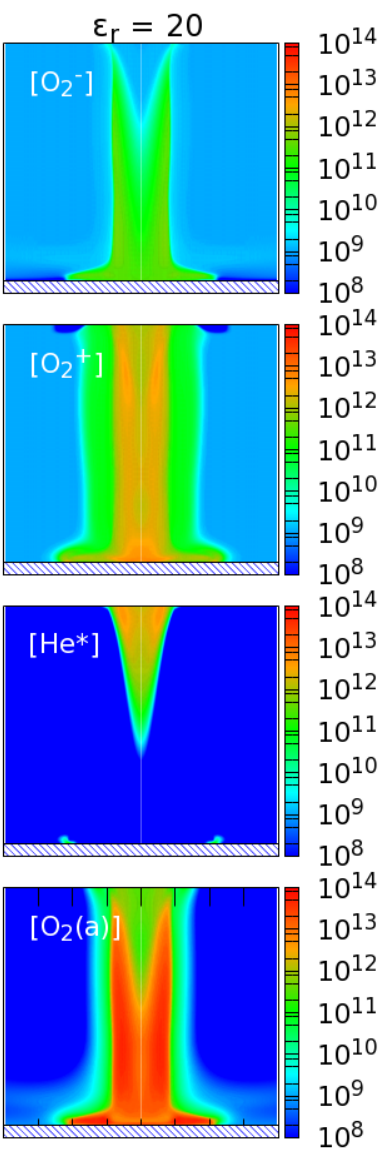

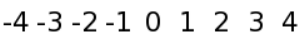

$\mathrm{r}[\mathrm{mm}]$

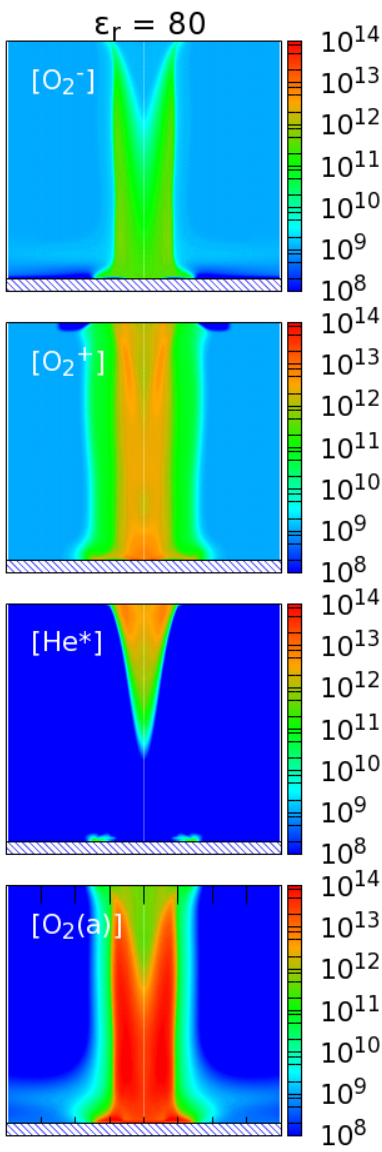

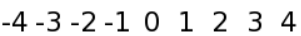

$\mathrm{r}[\mathrm{mm}]$

Figure 3. Cross section of spatial distribution of species densities in the plasma plume at $t=600$ ns. From left to right: $\epsilon_{r}=4,20$ and 80. From top to bottom: $\mathrm{O}_{2}^{-}, \mathrm{O}_{2}^{+}$, $\mathrm{He}^{*}$ and $\mathrm{O}_{2}(\mathrm{a})$.

the discharge front where it is being created by electron-impact reactions and in the region of very low $\mathrm{O}_{2}$ density $(<1 \%)$. That is due to the fast quenching of $\mathrm{He}^{*}$ through Penning ionization of $\mathrm{O}_{2}$ when $\mathrm{O}_{2}$ is present. The density of He metastable has been measured in Winter et al. 2015b] in the plume of a MHz-driven He jet and has been shown to have spatial distribution similar to the one presented here, with values around $10^{13} \mathrm{~cm}^{-3}$ between the tube nozzle and $4 \mathrm{~mm}$ downwards. Moreover, in a recent work Pouvesle et al. 2018, it has been shown a simple way to follow the time evolution of this density in experiments, relying on the late time evolution of the transitions emitted from the $\mathrm{N}_{2}^{+}(B)$ state. On the other hand, $\mathrm{O}_{2}^{-}$and $\mathrm{O}_{2}(\mathrm{a})$ require $\mathrm{O}_{2}$ to be produced and thus are present mostly in the region with $\mathrm{O}_{2}$ density higher than $1 \%$. That is not the case with $\mathrm{O}_{2}^{+}$, since $\mathrm{O}_{2}^{+}$is converted into the dominant ion by charge tranfer reactions from $\mathrm{He}^{+}$and $\mathrm{He}_{2}^{+}$, as well as by Penning ionization, even in the region of low $\mathrm{O}_{2}$ density. Finally, we can notice that $\mathrm{O}_{2}^{+}$and $\mathrm{O}_{2}($ a) densities close to the target tend to be proportional to $\epsilon_{r}$. 
In Figs. 4 and 5 we assess the influence of the target permittivity on the dischargetarget interaction in terms of the electric field between the plasma and the dielectric during the radial spreading of the discharge on the target. In Fig. 4 the temporal evolution of the maximum axial component of electric field $E_{z}$, on the surface at $z=0$ and for all $r$, directed from the plasma towards the target, is depicted. Then, in Fig. 5 the maximum outwards directed radial component of electric field $E_{r}$ in the plasma, very close to the target, is presented as function of time. The maximum of $E_{r}$ on the discharge front while spreading over the target can be placed at different positions above the target, but these are always between $z=0.25 \mathrm{~mm}$ and $z=0$ (target surface). The results are obtained with a temporal resolution of $1 \mathrm{~ns}$.

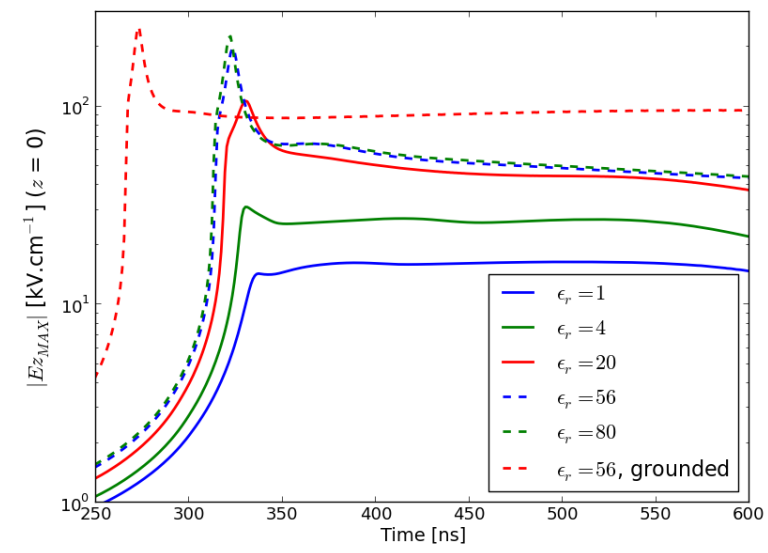

Figure 4. Temporal profiles of the maximum $\left|E_{z}\right|$ while the discharge is spreading radially over the target surface, for 6 different targets.

Fig. 4 shows firstly the time of impact of the discharges on the target, when $\left|E_{z}\right|$ at $z=0$ starts to quickly increase. Such high peaks of $E_{z}$ at discharge impact have also been reported in Lazarou et al. 2018] with a target with $\epsilon_{r}=8$ and in Yan and Economou [2016] with a grounded target. Then, after the impact, the maximum $\left|E_{z}\right|$ at $z=0$ between the plasma and the target increases with $\epsilon_{r}$ and the difference can reach a factor 5. This result agrees with Gauss's law at the target surface with surface charge density $\sigma=0$ : $\epsilon_{0} E_{z \rightarrow z^{+}}+\epsilon_{0} \epsilon_{r} E_{z \rightarrow z^{-}}=\sigma$; where $E_{z \rightarrow z^{-}}$inside the target is positive and $E_{z \rightarrow z^{+}}$between the plasma and the target is negative and has magnitude proportional to $\epsilon_{r}$. Moreover, $\left|E_{z}\right|$ at $z=0$ is higher with grounded target, due to the proximity of the ground. It is noticeable that for every case the maximum $\left|E_{z}\right|$, always on the discharge front and thus at different radial positions, stays almost constant during the radial spreading. As a consequence, more positive charge deposition on the target surface is expected with higher $\epsilon_{r}$.

As far as $E_{r}$ is concerned, Fig. 5 shows that in the discharge front spreading over the target surface, $E_{r}$ is inversely proportional to $\epsilon_{r}$, as in Wang et al. [2016]. In fact, when the discharge starts charging the target, with higher capacitance (proportional to $\left.\epsilon_{r}\right)$ the electric potential of the whole target is slowly raised. On the other hand, with lower capacitance, the rise of electric potential in the target is more localized, which 


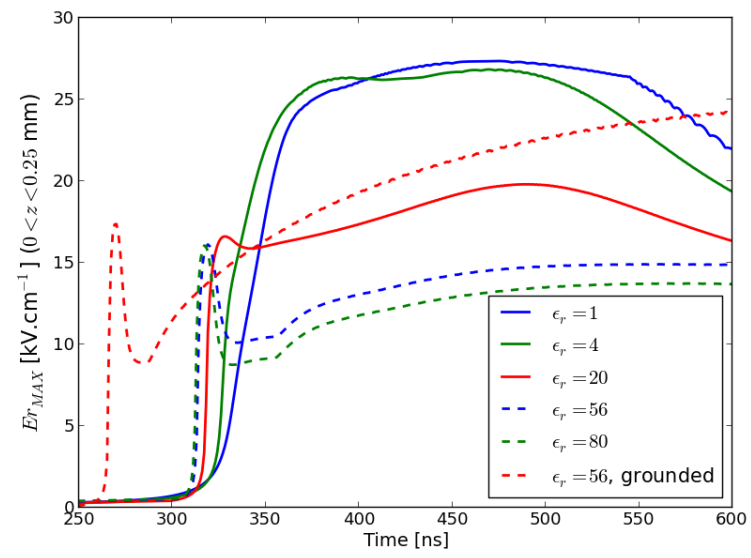

Figure 5. Temporal profiles of the maximum $E_{r}$ at $0<z<0.25 \mathrm{~mm}$, while the discharge is spreading radially over the target surface, for 6 different targets.

quickly leads to the depletion of the axial component of electric field and the rise of the radial component. As a result, slower spreading is expected with higher $\epsilon_{r}$, which has been verified in Fig. 2. With grounded target, despite the high $\epsilon_{r}=56$, as the target tends to be grounded, $E_{r}$ at the discharge front is higher than with a floating target with the same permittivity. In Fig. 6 we observe the effects that these temporal evolutions of the maximum of $\left|E_{z}\right|$ and $E_{r}$ have on the charge deposition on the target surface. In particular, Fig. 6 shows the radial profiles of surface charge density $\sigma$ while the discharge is spreading over the target surface, approximately $100 \mathrm{~ns}$ after the times of impact reported in table 1 .

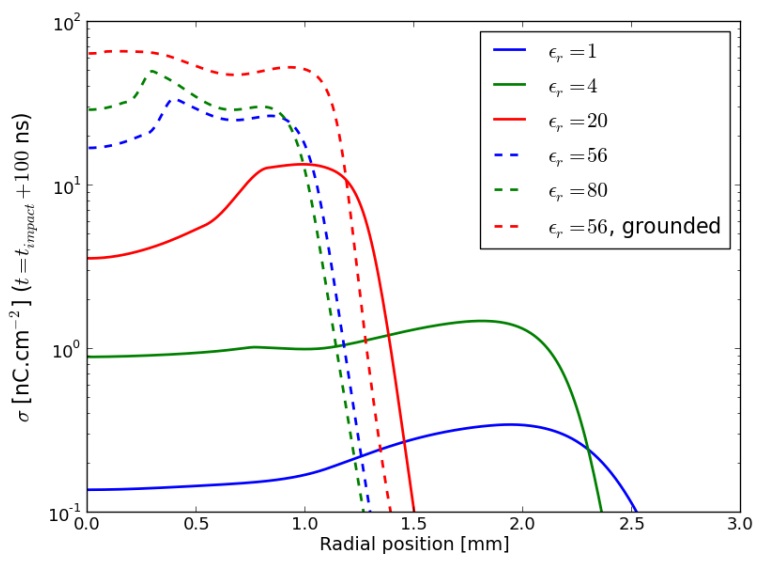

Figure 6. Radial profiles of the surface charge density $\sigma$ while the discharge is spreading radially over the target surface, $100 \mathrm{~ns}$ after the time of impact, for 6 different targets.

It can be noticed that tendentiously the radial spreading is proportional to $E_{r}$ presented in Fig. 5. Moreover, the values of $\sigma$ are proportional to $\left|E_{z}\right|$ shown in Fig. 4 and thus are highly dependent on the target permittivity, varying on more than two orders of magnitude between $\epsilon_{r}=1$ and 80. The proportionality of $\sigma$ with $\epsilon_{r}$ has 
also been verified in Wang et al. 2016. When the target is grounded, $\sigma$ reaches even higher values, over $50 \mathrm{nC} . \mathrm{cm}^{-2}$. It is also visible that in most cases $\sigma$ is higher at the discharge front than behind the front, as is also the case in Wang et al. [2016]; Zheng et al. 2018; Lazarou et al. 2018; Schweigert et al. 2019. In fact, behind the front, as the region of positive charge separation has moved, the electric field generated by the plasma towards the target decreases and some negative charge deposition takes place until a local balance with the upwards electric field created by the positive surface charge is reached. In Wang et al. [2016]; Ning et al. 2018); Zheng et al. 2018]; Lazarou et al. [2018]; Schweigert et al. [2019], with targets of $\epsilon_{r}=2,5,8,10$, the surface charge density is reported to have values between the ones in Fig. 5 for $\epsilon_{r}=4$ and $\epsilon_{r}=20$.

\subsection{Charging of the target surface and electric field experienced by the target}

In this section we evaluate how the dynamics with different targets affects the charging of the target surface and the electric field inside the target both during the pulse of applied voltage and after the fall of the pulse. Fig. 7 shows the temporal evolution of the total charge $Q$ deposited on the surface of the six different targets during those intervals. A vertical black dashed line is added at $t=600 \mathrm{~ns}$, to notice the time when the applied voltage starts decreasing, reaching zero at $t=650 \mathrm{~ns}$.

It is visible in Fig. 7 that the positive charging of the surface grows until the end of the pulse. The growth of $Q$ is dependent on the target and proportional to $\epsilon_{r}$. At $t=650 \mathrm{~ns}, Q$ of the floating target with lowest $\epsilon_{r}$ is about 5 times lower than $Q$ of the floating target with $\epsilon_{r}=80$. This result is expected, as the capacitance of the target, i.e. the amount of charge required to raise its electric potential, is proportional to $\epsilon_{r}$. When the target is grounded, $Q$ is significantly higher than in any of the floating targets. Then, after $t=650 \mathrm{~ns}, Q$ decreases, which means that globally negative charge deposition takes place. $Q$ always remains positive, although locally there can be negative $\sigma$ values. We can notice that $1000 \mathrm{~ns}$ after the fall of the pulse, $Q$ becomes almost stable in the cases of floating target, with low values below $0.1 \mathrm{nC}$, while with grounded target $Q$ remains rather high. Locally, the temporal dynamics of charge deposition is more complex. The temporal evolution of $\sigma$ at $r=0$ is presented in Fig. 8, for the six different targets.

Fig. 8 shows that the local charging of the target, both in rate and in value, is also proportional to $\epsilon_{r}$, as expected from Figs. 4 and 6. With $\epsilon_{r}=1$, the maximum $\sigma$ at $r=0$ is reached at $t=679 \mathrm{~ns}$ with $0.418{\mathrm{nC} . \mathrm{cm}^{-2}}^{-2}$ and with $\epsilon_{r}=4$ at $t=406 \mathrm{~ns}$ with $1.04 \mathrm{nC} . \mathrm{cm}^{-2}$. With higher $\epsilon_{r}$ and floating target, the maximum of $\sigma$ at $r=0$ is reached immediately after the impact and can be dozens or hundreds of times higher. Then, as the discharge spreads, with floating targets the downwards electric field generated by the plasma decreases at $r=0$ and some negative charge deposition takes place until a local balance with the upwards electric field created by the positive surface charge is reached. This process has been described in more detail in Viegas et al. 2018b. In Fig. 8 we notice that the decrease of $\sigma$ is more pronounced for higher $\epsilon_{r}$. When the applied 


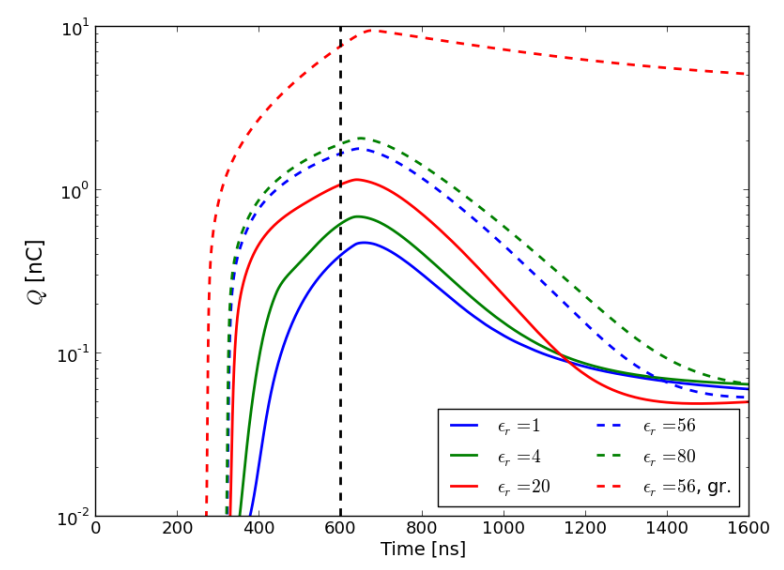

Figure 7. Temporal profiles of the total charge deposited on the target surface, for 6 different targets. A vertical black dashed line is added at $t=600 \mathrm{~ns}$ when the applied voltage starts decreasing.

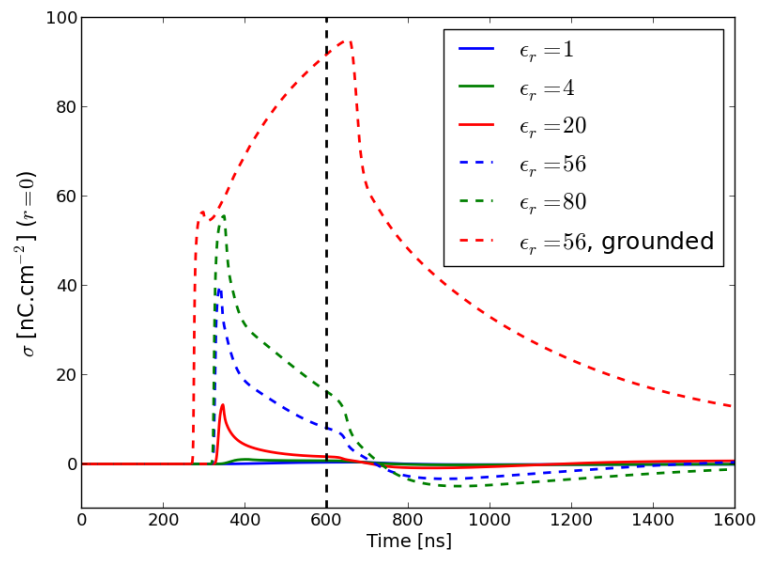

Figure 8. Temporal profiles of the surface charge density $\sigma$ deposited on the target surface at $r=0$, for 6 different targets. A vertical black dashed line is added at $t=600$ ns when the applied voltage starts decreasing.

voltage falls, as the plasma potential and the electric field from the plasma towards the target decrease, again negative charge deposition takes place. This process is not radially uniform. The positive charge on the surface is more quickly neutralized at $r=0$ than at other positions. Then, as the potential of the target is still higher than that of the plasma, negative charge deposition continues and $\sigma$ reaches negative values at the center, as has also been shown experimentally in Slikboer et al. [2019], even though $Q$ is still positive. Again, the negative charge deposition is more visible for higher $\epsilon_{r}$. For $\epsilon_{r}=80, \sigma$ can reach $-4.96 \mathrm{nC} . \mathrm{cm}^{-2}$ at $r=0$ at $t=917 \mathrm{~ns}$, before positive charge deposition takes place again to slowly neutralize the target. With grounded target, the surface charge dynamics is different. As the ground is close, the electric field towards the target is higher and thus surface charge continues increasing until the end of the pulse, both globally and locally. After the end of the pulse, $\sigma$ takes a much longer time to neutralize in the case with grounded target. 
In Fig. 9 we assess the impact that the previously described dynamics has on the electric field inside the different targets. We evaluate the temporal profiles of the axial component of electric field $E_{z}$ at $r=0$, directed downwards inside the target and averaged through the $0.5 \mathrm{~mm}$ thickness of the targets. In Fig. 9-a) is shown the contribution to the electric field exclusively of surface charges $E_{z a v \sigma}$. Then, the contribution of net charge in volume $E_{z a v \rho}$ is presented in Fig. 9.-b). Finally, the total average field $E_{z a v}$ is evaluated in Fig. 9fc). These temporal profiles are represented with $1 \mathrm{~ns}$ resolution. However, the values measured in experiments are result of acquisition lasting $100 \mathrm{~ns}$ [Viegas et al., 2018b] or $25 \mathrm{~ns}$ [Slikboer et al., 2019]. Hence, the comparison with experimental results requires averaging the numerical results over the time of acquisition. In Fig. 9-d) $E_{z a v}(t)$ is presented with 1 ns resolution, averaged over 25 ns and over $100 \mathrm{~ns}$, for two targets at floating potential $\left(\epsilon_{r}=4\right.$ and $\left.\epsilon_{r}=56\right)$. This allows to evaluate the effect of averaging, and thus of temporal acquisition, on the results.
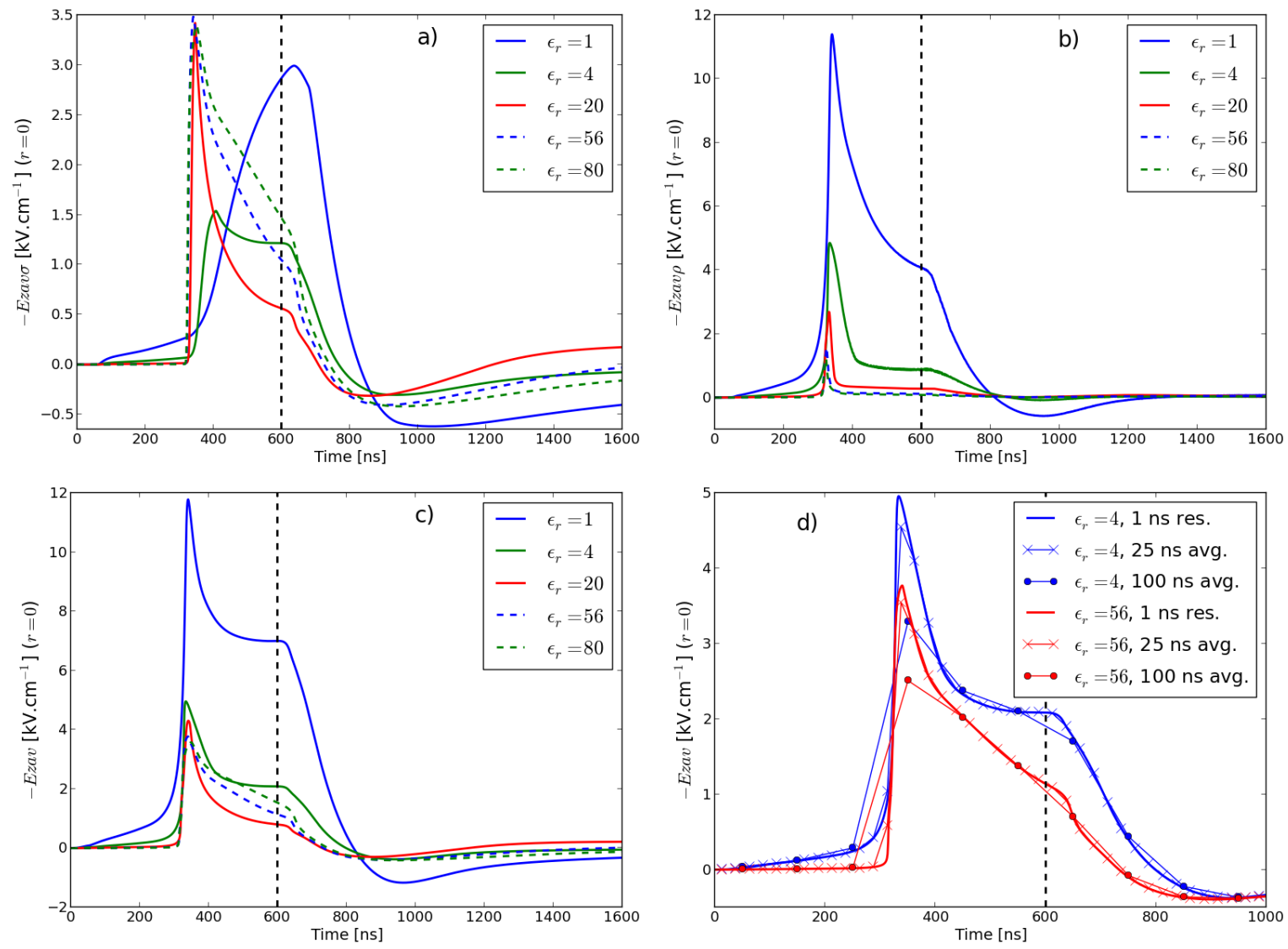

Figure 9. Temporal profiles of the downwards $E_{z}$, averaged through the target thickness, at $r=0$, for 5 different targets at floating potential: a) due exclusively to $\sigma, E_{z a v \sigma}$; b) due exclusively to $\rho, E_{z a v \rho}$; c) total, $E_{z a v}$. d) $E_{z a v}$ for $\epsilon=4,56$ : with $1 \mathrm{~ns}$ resolution; averaged over $25 \mathrm{~ns}$; averaged over $100 \mathrm{~ns}$. A vertical black dashed line is added at $t=600 \mathrm{~ns}$ when the applied voltage starts decreasing.

Fig. 9-a) shows that the shape of the temporal profiles of $E_{z a v \sigma}$ is approximately 
the same as that of $\sigma$ at the same position $r=0$, both during and after the pulse of applied voltage. However, the relation between the values of $E_{z a v \sigma}$ and $\sigma$ is not the same for every target. For example, the maximum of $\left|E_{z a v \sigma}\right|$ at $r=0$ is the same for $\epsilon_{r}=20,56$ and 80, while the maximum of $\sigma$ at $r=0$ is almost three times higher for $\epsilon_{r}=80$ than for $\epsilon_{r}=20$. In fact, with lower $\epsilon_{r}$, the same $|\sigma|$ provides higher $\left|E_{z a v \sigma}\right|$, in agreement with Gauss's law at the target surface: $\epsilon_{0} E_{z \rightarrow z^{+}}+\epsilon_{0} \epsilon_{r} E_{z \rightarrow z^{-}}=\sigma$. As a result, although $\sigma$ is proportional to $\epsilon_{r}, E_{\text {zav } \sigma}$ ends up having the same order of magnitude for every target at floating potential. When the target with $\epsilon_{r}=56$ is grounded (not shown here for sake of clarity of the figures), $\left|E_{z a v \sigma}\right|$ at $r=0$ rises during the pulse, up to 18 $\mathrm{kV} . \mathrm{cm}^{-1}$, and then decreases following the same temporal profile of $\sigma$. Therefore, it is much higher than in all the floating target cases.

Although the maximum electric field in the discharge front, studied in Fig. 4, is dependent on $\epsilon_{r}$, in general the plasma characteristics and the total net charge in the plasma, specially behind the front, are independent of $\epsilon_{r}$. Then, in agreement with Gauss's law, the electric field from the plasma penetrates more into targets of lower $\epsilon_{r}$. As a result, Fig. 9-b) shows that $\left|E_{\text {zavo }}\right|$ inside the target is inversely proportional to $\epsilon_{r}$. With $\epsilon_{r}=56$ and grounded target (not shown here for sake of clarity of the figures), $\left|E_{z a v \rho}\right|$ is relatively low but is higher than with floating target with the same permittivity, due to the lower distance between the plasma and the ground. By comparing Figs. 94a) and 9-b), we notice that for $\epsilon_{r}=1$ most of the electric field inside the target is due to $\rho$, while for $\epsilon_{r} \geq 20, E_{z a v \sigma}$ is the dominant contribution, except at the moment of impact when $\left|E_{z a v \rho}\right|$ reaches almost the same values as $\left|E_{z a v \sigma}\right|$. For $\epsilon_{r}=4$, both contributions are almost equally important.

Then, the result of the different contributions to the electric field can be observed in Fig. 9-c), where the total $E_{z a v}$ at $r=0$ is represented. $\left|E_{z a v}\right|$ at $r=0$ for grounded target with $\epsilon_{r}=56$ (not shown here for sake of clarity of the figures), almost exclusively due to $\sigma$, is significantly higher than all those represented in Fig. 9-c). It increases until the end of the pulse, when it reaches $18 \mathrm{kV} \cdot \mathrm{cm}^{-1}$. This value agrees in order of magnitude with those reported in Norberg et al. [2015] inside 5 mm-thick grounded targets of different permittivities. Then, $\left|E_{z a v}\right|$ at $r=0$ slowly decreases but remains directed towards the grounded plane, with $2.84 \mathrm{kV} . \mathrm{cm}^{-1}$ at $t=1600 \mathrm{~ns}$. Concerning the targets at floating potential, Fig. 9 shows that the electric field experienced by the target with $\epsilon_{r}=1$ is significantly higher than for all the other floating targets. Then, for floating targets with relative permittivity between 4 and 80, $E_{z}$ experienced by the target at $r=0$ ends up having the same order of magnitude. In all cases, the maximum of $\left|E_{z a v}\right|$ at $r=0$, at the time of impact, is between 3 and $5 \mathrm{kV} \cdot \mathrm{cm}^{-1}$. Then, $\left|E_{z a v}\right|$ decreases but always remains between 1 and $5 \mathrm{kV} \cdot \mathrm{cm}^{-1}$ until the end of the pulse. This result agrees with the simulations in Schweigert et al. [2019] where the maximum electric field inside a dielectric with $\epsilon_{r}=4$ is less than $10 \mathrm{kV} \cdot \mathrm{cm}^{-1}$. After the end of the pulse, the electric field experienced by the targets approaches zero but can be directed upwards with values up to $0.5 \mathrm{kV} \cdot \mathrm{cm}^{-1}$. We can conclude that the values of electric field measured inside a $0.5 \mathrm{~mm}$-thick BSO target with $\epsilon_{r}=56$ at floating 
potential exposed to a positive pulsed plasma jet, as in Viegas et al. 2018b]; Slikboer et al. [2019], are representative of the electric field that all dielectric targets with $\epsilon_{r} \geq 4$, with approximately the same thickness and at a floating potential, are exposed to.

Finally, Fig. 9-d) shows the importance of temporal resolution and time-averaging. In fact, it is shown that averaging over $25 \mathrm{~ns}$ leads only to a small difference with respect to the 1 ns-resolved results. However, the peak of the electric field can change by 0.3 $\mathrm{kV} . \mathrm{cm}^{-1}$ due to the $25 \mathrm{~ns}$-averaging. Then, when averaging over $100 \mathrm{~ns}$, the peak clearly changes with respect to the resolved result by $1.5 \mathrm{kV} . \mathrm{cm}^{-1}$ and the temporal evolution of $E_{z a v}$ is also severely affected. This result reveals the importance of temporal resolution in experimental measurements and of post-treatment of numerical data to comply with experiments, as was the case in Slikboer et al. [2019].

\section{Conclusions}

This work presents a numerical study of the influence of dielectric permittivity on the interaction between a positive pulsed He plasma jet and a dielectric target. The numerical description of the plasma-target interaction has been validated with a floating target with $\epsilon_{r}=56$ through quantitative comparisons with experiments in Slikboer et al. 2019. Here, six different targets are studied: five targets at floating potential with relative permittivities $\epsilon_{r}=1,4,20,56$ and 80; and one grounded target of permittivity $\epsilon_{r}=56$. Particular attention is given to the charging of the target and to the electric field inside the target.

It is verified that the discharge spreads radially faster over targets of lower permittivity and thus lower capacitance. Moreover, targets with higher permittivity acquire more positive charge on their surface, both globally during the interaction with the plasma and locally at the impact point after the impact of the discharge. Between the impact of the discharge and the end of the applied voltage pulse, negative charge deposition takes place locally on all floating targets, even though globally they keep charging positively. This negative charge deposition tends to balance the electric field created by the plasma with the electric field originated by the charges on the target surface. After the pulse of applied voltage, negative charge deposition takes place on all the targets, both locally and globally. Locally, at the point of impact, negative surface charge densities are reached on the floating targets, reaching up to $-5 \mathrm{nC} . \mathrm{cm}^{-2}$ with $\epsilon_{r}=80$.

It is found that the order of magnitude of the electric field inside the dielectric targets is the same for floating targets with $\epsilon_{r} \geq 4$. Following Gauss's law, the electric field originated by net charge in the volume of the plasma is higher inside targets of lower permittivity. Conversely, as surface charge density is much higher with higher $\epsilon_{r}$, it tends to create higher electric field values inside targets of higher permittivity. As a result, despite the different $\rho$ and $\sigma$ contributions, for all these targets the maximum of the axial component of electric field averaged through the target thickness, $\left|E_{z a v}\right|$, at $r=0$, immediately after the time of impact, is between 3 and $5 \mathrm{kV} \cdot \mathrm{cm}^{-1}$. Then, 
after the impact, $\left|E_{z a v}\right|$ decreases but always remains between 1 and $5 \mathrm{kV} \cdot \mathrm{cm}^{-1}$ until the end of the pulse for these targets. After the end of the pulse, $E_{z a v}$ experienced by the targets approaches zero but can be directed upwards with values up to $0.5 \mathrm{kV} . \mathrm{cm}^{-1}$. For $\epsilon_{r}=1,\left|E_{z a v}\right|$ at $r=0$ is significantly higher than for all the other floating targets. We can conclude that the values of electric field measured inside a $0.5 \mathrm{~mm}$-thick BSO target with $\epsilon_{r}=56$ at floating potential exposed to a positive pulsed plasma jet, as in Viegas et al. 2018b; Slikboer et al. 2019, are representative of the electric field that all dielectric targets with $\epsilon_{r} \geq 4$, with approximately the same thickness and at a floating potential, are exposed to.

The influence of placing a grounded plane behind a target with $\epsilon_{r}=56$ is shown to be very important. Both the global and local surface charge are orders of magnitude higher when the target is grounded. The maximum of $\left|E_{z a v}\right|$ at $r=0$ takes the value of $18 \mathrm{kV} \cdot \mathrm{cm}^{-1}$, instead of $4 \mathrm{kV} \cdot \mathrm{cm}^{-1}$ when the same target has a floating potential. This result shows that, in applications, the thickness of the target and what lies behind it are determinant for the charging and electric field the target is exposed to. 


\section{Appendix: Chemistry reduction}

In section 2 two reaction schemes for $\mathrm{He}_{2} \mathrm{O}_{2}$ have been introduced: one more complete and one more reduced. The most complete scheme is taken from Liu et al. [2010]. Then, using that scheme, the 10 most important species in the $\mu$ s timescales under study have been identified by comparing their number densities in the simulated jet. The scheme reduction consists on keeping only those species: e, $\mathrm{O}_{2}^{-}, \mathrm{He}^{+}, \mathrm{He}_{2}^{+}, \mathrm{O}_{2}^{+}, \mathrm{He}$, $\mathrm{He}\left(2^{3} \mathrm{~S}, 2^{1} \mathrm{~S}\right), \mathrm{O}, \mathrm{O}_{2}, \mathrm{O}_{2}\left(a_{1} \Delta_{g}\right)$. In tables 2 and 3 we present the list of reactions and rate coefficients of the reduced reaction scheme used in this work. The rate coefficients of electron-impact reactions have been calculated with the electron Boltzmann equation solver BOLSIG+ Hagelaar and Pitchford, 2005], using the IST-Lisbon database of cross sections in LXCat Pancheshnyi et al. 2012; IST, 2018]. 
Numerical study of jet-target interaction: ...

\begin{tabular}{|c|c|}
\hline Reaction & Rate coefficient \\
\hline $\mathrm{He}+\mathrm{e} \rightarrow \mathrm{He}^{*}+\mathrm{e}$ & $k\left(\epsilon_{m}, \operatorname{mix}\right)$ \\
\hline $\mathrm{He}^{*}+\mathrm{e} \rightarrow \mathrm{He}+\mathrm{e}$ & $k\left(\epsilon_{m}, m i x\right)$ \\
\hline $\mathrm{O}_{2}+\mathrm{e} \rightarrow \mathrm{O}_{2}(a)+\mathrm{e}$ & $k\left(\epsilon_{m}, \operatorname{mix}\right)$ \\
\hline $\mathrm{O}_{2}(a)+\mathrm{e} \rightarrow \mathrm{O}_{2}+\mathrm{e}$ & $k\left(\epsilon_{m}, \operatorname{mix}\right)$ \\
\hline $\mathrm{O}_{2}+\mathrm{e} \rightarrow \mathrm{O}+\mathrm{O}+\mathrm{e}$ & $k\left(\epsilon_{m}, m i x\right)$ \\
\hline $\mathrm{O}_{2}(a)+\mathrm{e} \rightarrow \mathrm{O}+\mathrm{O}+\mathrm{e}$ & $k\left(\epsilon_{m}, m i x\right)$ \\
\hline $\mathrm{He}+\mathrm{e} \rightarrow \mathrm{He}^{+}+\mathrm{e}+\mathrm{e}$ & $k\left(\epsilon_{m}, m i x\right)$ \\
\hline $\mathrm{He}^{*}+\mathrm{e} \rightarrow \mathrm{He}^{+}+\mathrm{e}+\mathrm{e}$ & $k\left(\epsilon_{m}, m i x\right)$ \\
\hline $\mathrm{O}_{2}+\mathrm{e} \rightarrow \mathrm{O}_{2}^{+}+\mathrm{e}+\mathrm{e}$ & $k\left(\epsilon_{m}, m i x\right)$ \\
\hline $\mathrm{O}_{2}(a)+\mathrm{e} \rightarrow \mathrm{O}_{2}^{+}+\mathrm{e}+\mathrm{e}$ & $k\left(\epsilon_{m}, m i x\right)$ \\
\hline $\mathrm{He}^{+}+\mathrm{e} \rightarrow \mathrm{He}^{*}$ & $6.76 \times 10^{-13} \times T_{e}^{-0.5}$ \\
\hline $\mathrm{He}_{2}^{+}+\mathrm{e} \rightarrow \mathrm{He}^{*}+\mathrm{He}$ & $7.12 \times 10^{-15} \times\left(T_{e} / T_{g}\right)^{-1.5}$ \\
\hline $\mathrm{O}_{2}^{+}+\mathrm{e} \rightarrow \mathrm{O}+\mathrm{O}$ & $1.2 \times 10^{-8} \times T_{e}^{-0.7}$ \\
\hline $\mathrm{He}^{+}+\mathrm{e}+\mathrm{e} \rightarrow \mathrm{He}^{*}+\mathrm{e}$ & $7.38 \times 10^{-38} \times\left(T_{e} / T_{g}\right)^{-4.4}$ \\
\hline $\mathrm{He}_{2}^{+}+\mathrm{e}+\mathrm{e} \rightarrow \mathrm{He}^{*}+\mathrm{He}+\mathrm{e}$ & $2.8 \times 10^{-20}$ \\
\hline $\mathrm{O}_{2}^{+}+\mathrm{e}+\mathrm{e} \rightarrow \mathrm{O}_{2}+\mathrm{e}$ & $7.18 \times 10^{-27} \times T_{e}^{-4.5}$ \\
\hline $\mathrm{He}^{+}+\mathrm{e}+\mathrm{He} \rightarrow \mathrm{He}^{*}+\mathrm{He}$ & $7.4 \times 10^{-35} \times\left(T_{e} / T_{g}\right)^{-2.0}$ \\
\hline $\mathrm{He}_{2}^{+}+\mathrm{e}+\mathrm{He} \rightarrow \mathrm{He}^{*}+\mathrm{He}+\mathrm{He}$ & $3.5 \times 10^{-27}$ \\
\hline $\mathrm{O}_{2}^{+}+\mathrm{e}+\mathrm{O}_{2} \rightarrow \mathrm{O}_{2}+\mathrm{O}_{2}$ & $2.49 \times 10^{-29} \times T_{e}^{-1.5}$ \\
\hline $\mathrm{O}_{2}+\mathrm{e}+\mathrm{O}_{2} \rightarrow \mathrm{O}_{2}^{-}+\mathrm{O}_{2}$ & $2.26 \times 10^{-30} \times\left(T_{g} / 300\right)^{-0.5}$ \\
\hline $\mathrm{O}_{2}+\mathrm{e}+\mathrm{He} \rightarrow \mathrm{O}_{2}^{-}+\mathrm{He}$ & $1.0 \times 10^{-31}$ \\
\hline $\mathrm{He}^{+}+\mathrm{O}_{2}^{-} \rightarrow \mathrm{He}+\mathrm{O}_{2}$ & $2.0 \times 10^{-7} \times\left(T_{g} / 300\right)^{-1.0}$ \\
\hline $\mathrm{He}_{2}^{+}+\mathrm{O}_{2}^{-} \rightarrow \mathrm{He}+\mathrm{He}+\mathrm{O}_{2}$ & $1.0 \times 10^{-7}$ \\
\hline $\mathrm{He}_{2}^{+}+\mathrm{O}_{2}^{-}+\mathrm{M} \rightarrow \mathrm{He}+\mathrm{He}+\mathrm{O}_{2}+\mathrm{M}$ & $2.0 \times 10^{-25} \times\left(T_{g} / 300\right)^{-2.5}$ \\
\hline $\mathrm{O}_{2}^{+}+\mathrm{O}_{2}^{-} \rightarrow \mathrm{O}_{2}+\mathrm{O}_{2}$ & $2.0 \times 10^{-7} \times\left(T_{g} / 300\right)^{-0.5}$ \\
\hline $\mathrm{O}_{2}^{+}+\mathrm{O}_{2}^{-} \rightarrow \mathrm{O}_{2}+\mathrm{O}+\mathrm{O}$ & $1.01 \times 10^{-7} \times\left(T_{g} / 300\right)^{-0.5}$ \\
\hline $\mathrm{O}_{2}^{+}+\mathrm{O}_{2}^{-}+\mathrm{M} \rightarrow \mathrm{O}_{2}+\mathrm{O}_{2}+\mathrm{M}$ & $2.0 \times 10^{-25} \times\left(T_{g} / 300\right)^{-2.5}$ \\
\hline $\mathrm{He}+\mathrm{O}_{2}^{-} \rightarrow \mathrm{He}+\mathrm{O}_{2}+\mathrm{e}$ & $3.9 \times 10^{-10} \times \exp \left(-7400 / T_{g}\right)$ \\
\hline $\mathrm{He}^{*}+\mathrm{O}_{2}^{-} \rightarrow \mathrm{He}+\mathrm{O}_{2}+\mathrm{e}$ & $3.0 \times 10^{-10}$ \\
\hline $\mathrm{O}_{2}+\mathrm{O}_{2}^{-} \rightarrow \mathrm{O}_{2}+\mathrm{O}_{2}+\mathrm{e}$ & $2.7 \times 10^{-10} \times \exp \left(-5590 / T_{g}\right)$ \\
\hline $\mathrm{O}_{2}(a)+\mathrm{O}_{2}^{-} \rightarrow \mathrm{O}_{2}+\mathrm{O}_{2}+\mathrm{e}$ & $2.0 \times 10^{-10} \times\left(T_{g} / 300\right)^{0.5}$ \\
\hline
\end{tabular}

Table 2. List of reactions and rate coefficients of the reduced reaction scheme in use: part 1. Scheme reduced from the one in Liu et al. [2010]. $\mathrm{M}$ is any neutral $\left(\mathrm{He}\right.$ or $\left.\mathrm{O}_{2}\right)$. $T_{g}=300 \mathrm{~K}$ is the gas temperature. $\epsilon_{m}$ is the local mean electron energy. mix is the local gas mixture. $T_{e}=2 / 3 \epsilon_{m}$ is the electron temperature. The rate coefficients have units $\mathrm{cm}^{3} \mathrm{~s}^{-1}$ in the case of two-body reactions and $\mathrm{cm}^{6} \mathrm{~s}^{-1}$ in the case of three-body reactions.

Then, in section 3 the numerical results presented have been obtained using the reduced chemistry. The chemistry reduction does not change the general discharge dynamics and the time of impact of the discharge on the targets. In this appendix, 


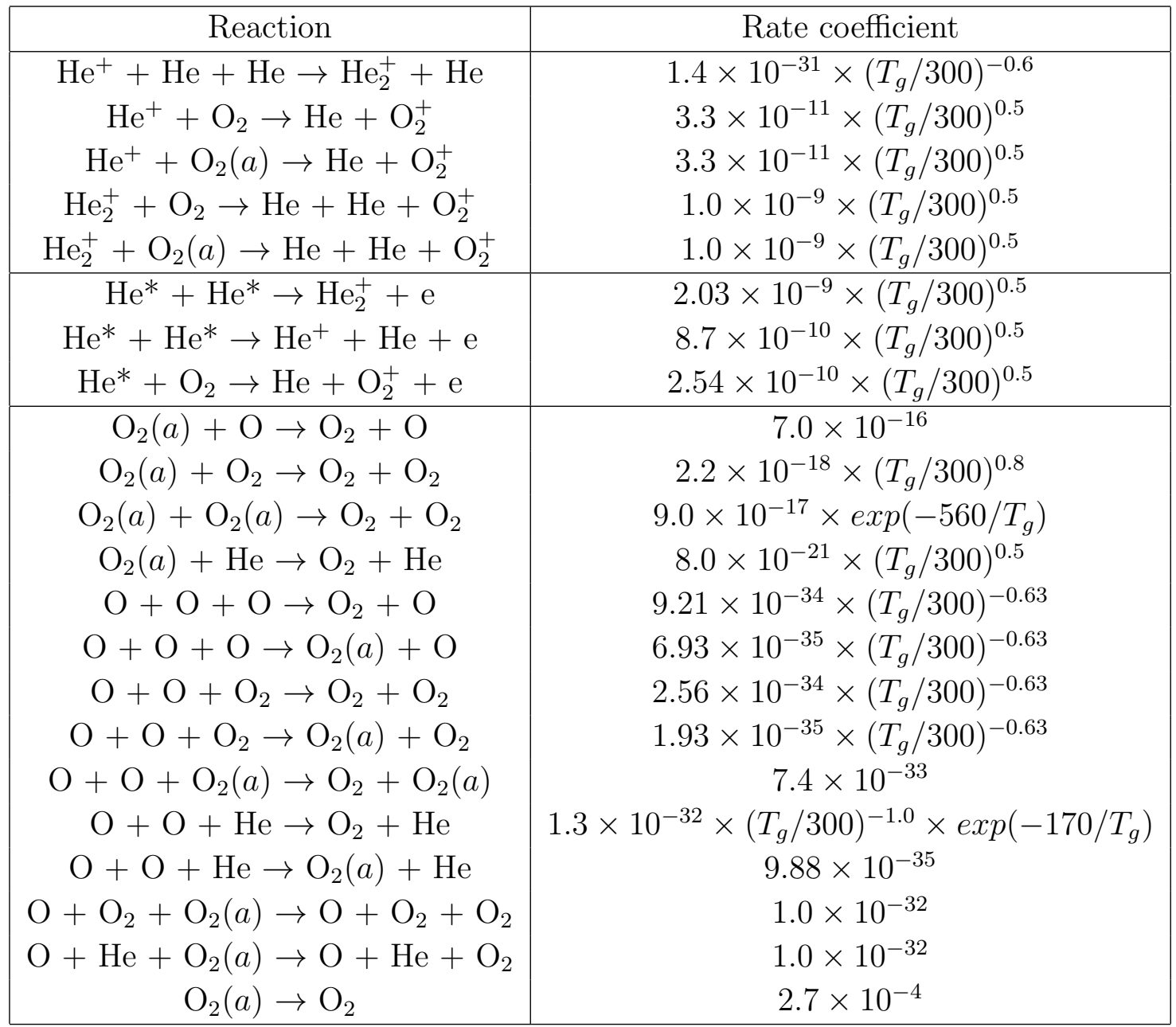

Table 3. List of reactions and rate coefficients of the reduced reaction scheme in use: part 2. Scheme reduced from the one in Liu et al. 2010. $T_{g}=300 \mathrm{~K}$ is the gas temperature. $\epsilon_{m}$ is the local mean electron energy. mix is the local gas mixture. $T_{e}=2 / 3 \epsilon_{m}$ is the electron temperature. The rate coefficients have units of $\mathrm{s}^{-1}$ in the case of one-body decay, of $\mathrm{cm}^{3} \mathrm{~s}^{-1}$ in the case of two-body reactions and of $\mathrm{cm}^{6} \mathrm{~s}^{-1}$ in the case of three-body reactions.

we assess the effect of the chemistry reduction on the electric field inside the target, both at $r=0$ and radially. For that purpose, we use the targets at floating potential with $\epsilon_{r}=4$ and $\epsilon_{r}=56$ and test the two chemistry schemes. Fig. 10 presents the temporal profiles of $E_{z}$, averaged through the target thickness, due exclusively to net charge density $\rho, E_{z a v \rho}$, at $r=0$, for the two targets and the two chemistry schemes. We can conclude from that figure that the chemistry reduction does not significantly impact charge separation in volume and $E_{z a v \rho}$.

Then, in Fig. 11, the temporal profiles of $E_{z}$, averaged through the target thickness, due exclusively to surface charge density $\sigma, E_{z a v \sigma}$, at $r=0$, are presented. In this case, the difference between the full and reduced chemistries is visible. In fact, $|\sigma|$ is about $10 \%$ lower when using the reduced chemistry than in the case with the full chemistry. In particular, after the end of the pulse, at the neutralization of the plasma and the 


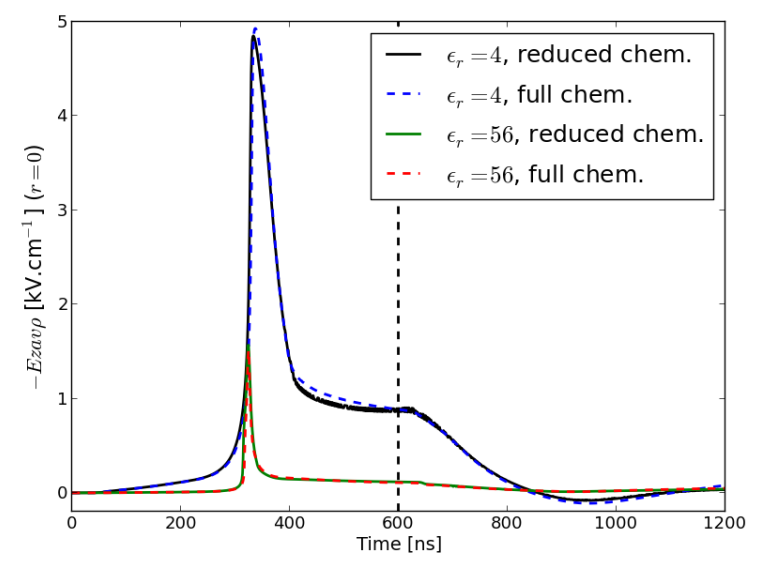

Figure 10. Temporal profiles of the downwards $E_{z}$, averaged through the target thickness, due exclusively to $\rho$, at $r=0$, for $\epsilon_{r}=4$ and $\epsilon_{r}=56$ and two different chemistry schemes. A vertical black dashed line is added at $t=600 \mathrm{~ns}$ when the applied voltage starts decreasing.

target, the negative charge deposition is slightly different. Still, we should notice that the same dynamics is observed with both reaction schemes.

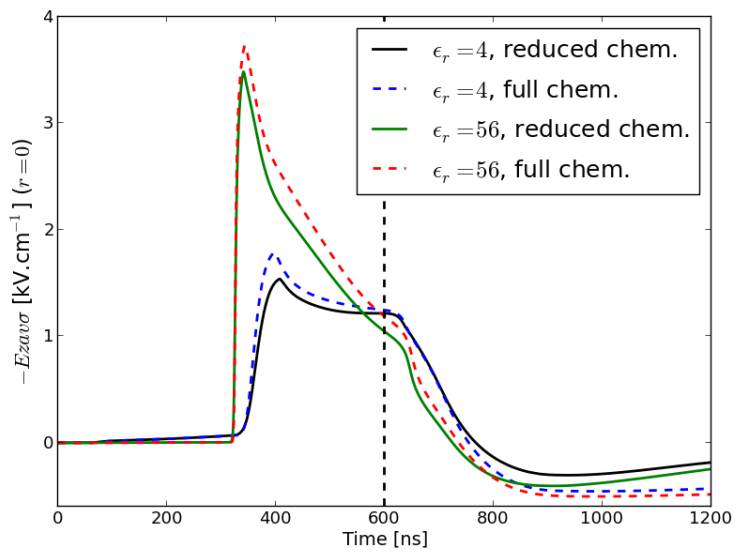

Figure 11. Temporal profiles of the downwards $E_{z}$, averaged through the target thickness, due exclusively to $\sigma$, at $r=0$, for $\epsilon_{r}=4$ and $\epsilon_{r}=56$ and two different chemistry schemes. A vertical black dashed line is added at $t=600$ ns when the applied voltage starts decreasing.

In Fig. 12, the temporal profiles of the total $E_{z a v}$ are presented, now at a different radial position, $r=1 \mathrm{~mm}$. We can notice that the time it takes the discharge to reach that radial position is independent of the chemistry scheme. As the discharge spreads radially faster with lower permittivity, it is visible that $E_{z a v}$ rises first and also decreases faster with $\epsilon_{r}=4$ than with $\epsilon_{r}=56$. Then, for both targets, as at $r=0$, the different chemistry schemes lead to a small difference after the end of the pulse, due to the different negative charge deposition.

In Fig. 13 are represented the temporal profiles of the radial component of electric 


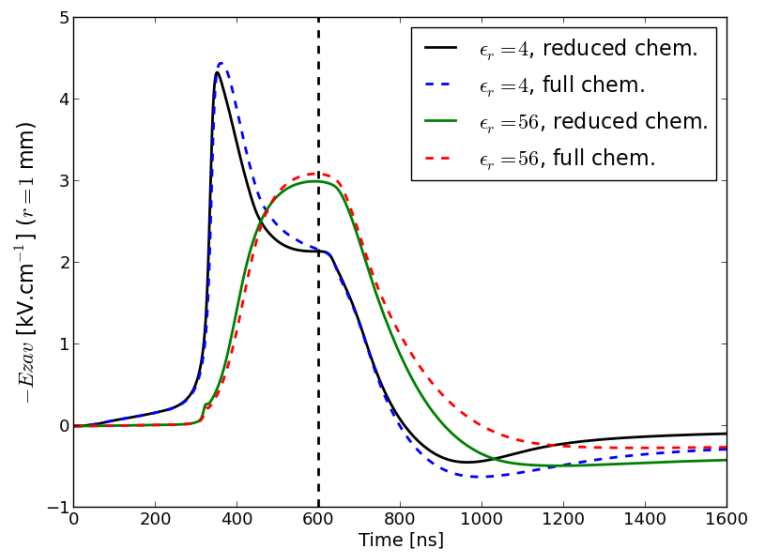

Figure 12. Temporal profiles of the downwards $E_{z}$, averaged through the target thickness, at $r=1 \mathrm{~mm}$, for $\epsilon_{r}=4$ and $\epsilon_{r}=56$ and two different chemistry schemes. A vertical black dashed line is added at $t=600 \mathrm{~ns}$ when the applied voltage starts decreasing.

field, averaged through the target thickness, $E_{\text {rav }}$, at the same radial position $r=1$ $\mathrm{mm}$. Also for this electric field component, differences between the chemistry schemes are only noticed after the end of the pulse. As for $E_{z a v}$, a sharper peak of $E_{\text {rav }}$ at $r=1$ $\mathrm{mm}$ is present for $\epsilon_{r}=4$ due to the faster spreading than for $\epsilon_{r}=56$. Moreover, we can notice that $E_{\text {rav }}$ has values of the same order of magnitude as $E_{z a v}$ at the same radial position, with slightly higher positive maximum and slightly lower negative minimum. The values of $E_{\text {rav }}$ at $r=1 \mathrm{~mm}$ with $\epsilon_{r}=56$ approximately agree with those measured in Slikboer et al. [2019] in the same conditions.

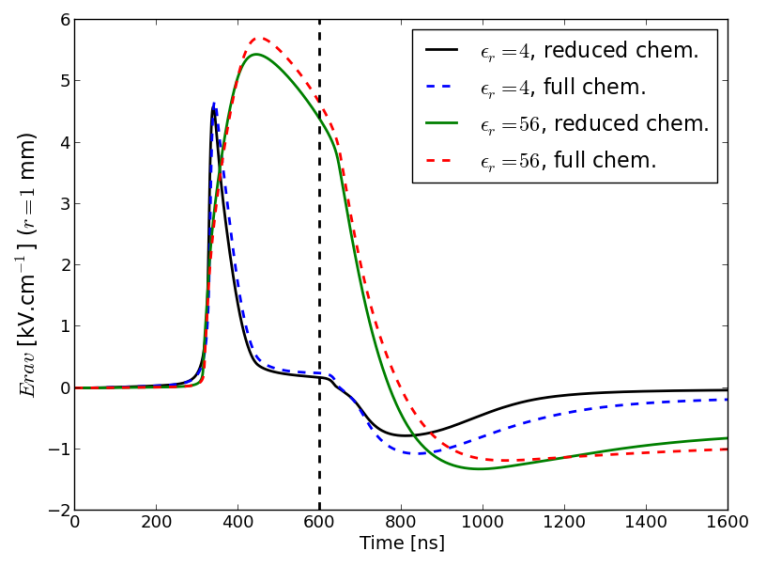

Figure 13. Temporal profiles of the outwards $E_{r}$, averaged through the target thickness, at $r=1 \mathrm{~mm}$, for $\epsilon_{r}=4$ and $\epsilon_{r}=56$ and two different chemistry schemes. A vertical black dashed line is added at $t=600 \mathrm{~ns}$ when the applied voltage starts decreasing. 


\section{Acknowledgements}

PV has been supported by French governmental fellowships attributed by the École Doctorale Ondes et Matière. This work has been done partially within the LABEX Plas@par project, and received financial state aid managed by the Agence Nationale de la Recherche (ANR), as part of the programme "Investissements d'avenir" under the reference ANR-11-IDEX-0004-02. Simulations presented in this work have been performed thanks to the computational resources of the cluster "Hopper" at École Polytechnique. This is a post-peer-review, pre-copyedit version of an article published in PCPP. The final authenticated version is available online at: https://link.springer.com/article/10.1007/s11090-019-10033-6

\section{References}

Alves, L. L., A. Bogaerts, V. Guerra, and M. M. Turner (2018), Foundations of modelling of nonequilibrium low-temperature plasmas, Plasma Sources Sci. Technol., 27(023002).

Babaeva, N. Y., G. V. Naidis, V. A. Panov, R. Wang, S. Zhang, C. Zhang, and T. Shao (2019), Plasma bullet propagation and reflection from metallic and dielectric targets, Plasma Sources Sci. Technol., 28(095006).

Bogaczyk, M., R. Wild, L. Stollenwerk, and H.-E. Wagner (2012), Surface charge accumulation and discharge development in diffuse and filamentary barrier discharges operating in He, $\mathrm{N}_{2}$ and mixtures, J. Phys. D: Appl. Phys., 45(465202).

Bourdon, A., T. Darny, F. Pechereau, J. Pouvesle, P. Viegas, S. Iséni, and E. Robert (2016), Numerical and experimental study of the dynamics of a $\mu$ s helium plasma gun discharge with various amounts of $\mathrm{N}_{2}$ admixture, Plasma Sources Sci. Technol., $25(035002)$.

Breden, D., and L. L. Raja (2014), Computational study of the interaction of cold atmospheric helium plasma jets with surfaces, Plasma Sources Sci. Technol., 23(065020).

Collet, G., E. Robert, A. Lenoir, M. Vandamme, T. Darny, S. Dozias, C. Kieda, and J. M. Pouvesle (2014), Plasma jet-induced tissue oxygenation: potentialities for new therapeutic strategies, Plasma Sources Sci. Technol., 23(012005).

Fridman, G., G. Friedman, A. Gutsol, A. B. Shekhter, V. N. Vasilets, and A. Fridman (2008), Applied plasmas medicine, Plasma Process. Plym., 5, 503-533.

Graves, D. B. (2015), Low temperature plasma biomedicine: A tutorial review, Phys. Plasmas, 21.

Hagelaar, G., and L. Pitchford (2005), Solving the Boltzmann equation to obtain electron transport coefficients and rate coefficients for fluid models, Plasma Sources Sci. Technol. , 14 (722).

Hofmans, M., and A. Sobota (2019), Influence of a target on the electric field profile in a khz atmospheric pressure plasma jet with the full calculation of the stark shifts, $J$. Appl. Phys., 125(043303). 
IST (2018), IST-Lisbon database, www.lxcat.net, retrieved on June 2018.

Ji, L., W. Yan, Y. Xia, and D. Liu (2018), The effect of target materials on the propagation of atmospheric-pressure plasma jets, J. Appl. Phys., 123(183302).

Kawasaki, T., Y. Arai, and T. Takada (1991), Two-dimensional measurement of electrical surface charge distribution on insulating materials by electrooptic pockels effect, Japanese Journal of Applied Physics, Part 1: Regular Papers and Short Notes and Review Papers, 30(6), 1262-1265.

Kim, S. J., T. H. Chung, S. H. Bae, and S. H. Leem (2010), Induction of apoptosis in human breast cancer cells by a pulsed atmospheric pressure plasma jet, Appl. Phys. Lett., $97(023702)$.

Klarenaar, B., O. Guaitella, R. Engeln, and A. Sobota (2018), How dielectric, metallic and liquid targets influence the evolution of electron properties in a pulsed he jet measured by Thomson and Raman scattering, Plasma Sources Sci. Technol., $27(085004)$.

Kong, M. G., G. Kroesen, G. Morfill, T. Nosenko, T. Shimizu, J. van Dijk, and J. L. Zimmermann (2009), Plasma medicine: an introductory review, New Journal of Physics, 11, 115,012.

Laimer, J., and H. Stori (2007), Recent advances in the research on non-equilibrium atmospheric pressure plasma jets, Plasma Process. Polym., 4(3), 266-274.

Laroussi, M. (2015), Low-temperature plasma jet for biomedical applications: A review, IEEE Trans. Plasma Sci., 43, 703-12.

Laroussi, M., and T. Akan (2007), Arc-free atmospheric pressure cold plasma jets: A review, Plasma Process. Polym., 4(9), 777-788.

Lazarou, C., C. Anastassiou, I. Topala, A. S. Chiper, I. Mihaila, V. Pohoata, and G. E. Georghiou (2018), Numerical simulation of capillary helium and heliumoxygen atmospheric pressure plasma jets: propagation dynamics and interaction with dielectric, Plasma Sources Sci. Technol., 27(105007).

Liu, D., M. Rong, X. Wang, F. Iza, M. Kong, and P. Bruggeman (2010), Main species and physicochemical processes in cold atmospheric-pressure $\mathrm{He}+\mathrm{O}_{2}$ plasmas, Plasma Process. Polym., 7(846).

Lu, X., M. Laroussi, and V. Puech (2012), On atmospheric-pressure non-equilibrium plasma jets and plasma bullets, Plas Sources Sci. Technol., 21 (034005).

Lu, X., G. V. Naidis, M. Laroussi, and K. Ostrikov (2014), Guided ionization waves: Theory and experiments, Physics Reports, 540, 123-166.

Mirpour, S., H. Ghomi, S. Piroozmand, M. Nikkah, S. H. Tavassoli, and S. Z. Azad (2014), The selective characterization of nonthermal atmospheric pressure plasma jet on treatment of human breast cancer and normal cells, IEEE Trans. Plasma Sci., 42, $315-22$.

Naidis, G. V. (2011), Modelling of plasma bullet propagation along a helium jet in ambient air, J. Phys. D: Appl. Phys. , 44 (215203). 
Ning, W., D. Dai, Y. Zhang, Y. Han, and L. Li (2018), Effects of trace of nitrogen on the helium atmospheric pressure plasma jet interacting with a dielectric substrate, $J$. Phys. D.: Appl. Phys., 51 (125204).

Norberg, S., E. Johnsen, and M. Kushner (2015), Helium atmospheric pressure plasma jets touching dielectric and metal surfaces, J. Appl. Phys., 118(013301).

Pancheshnyi, S., S. Biagi, M. Bordage, G. Hagelaar, W. Morgan, A. Phelps, and L. Pitchford (2012), The LXCat project: Electron scattering cross sections and swarm parameters for low temperature plasma modeling, Chemical Physics, 398, 148.

Pouvesle, J., T. Darny, T. Maho, V. Puech, C. Douat, S. Dozias, and E. Robert (2018), Atomic rare gas metastable monitoring through nitrogen emission in atmospheric pressure plasma jets, Plasma Medicine, 8(1), 83-92.

Reuter, S., T. von Woedtke, and K.-D. Weltmann (2018), The kinpen - a review on physics and chemistry of the atmospheric pressure plasma jet and its applications, $J$. Phys. D: Appl. Phys., 51(233001).

Schmidt-Bleker, A., S. A. Norberg, J. Winter, E. Johnsen, S. Reuter, K. D. Weltmann, and M. J. Kushner (2015), Propagation mechanisms of guided streamers in plasma jets: the influence of electronegativity of the surrounding gas, Plasma Sources Sci. Technol. , 24 (035022).

Schutze, A., J. Y. Jeong, S. E. Babayan, J. Park, G. S. Selwyn, and R. F. Hicks (1998), The atmospheric-pressure plasma jet: a review and comparison to other plasma sources, IEEE Trans. Plasma Sci., 26(6), 1685-1694.

Schweigert, I. V., S. Vagapov, L. Lin, and M. Keidar (2019), Enhancement of atmospheric plasma jet-target interaction with an external ring electrode, J. Phys. D: Appl. Phys., 52(295201).

Slikboer, E., O. Guaitella, and A. Sobota (2016), Time-resolved electric field measurements during and after the initialization of a khz plasma jet-from streamers to guided streamers, Plasma Sources Sci. Technol. , 25(03LT04).

Slikboer, E., E. Garcia-Caurel, O. Guaitella, and A. Sobota (2017), Charge transfer to a dielectric target by guided ionization waves using electric field measurements, Plasma Sources Sci. Technol. , 26(035002).

Slikboer, E., A. Sobota, O. Guaitella, and E. Garcia-Caurel (2018), Imaging axial and radial electric field components in dielectric targets under plasma exposure, J. Phys. D: Appl. Phys. , 51 (115203).

Slikboer, E., P. Viegas, Z. Bonaventura, E. Garcia-Caurel, A. Sobota, A. Bourdon, and O. Guaitella (2019), Experimental and numerical investigation of the transient charging of a dielectric surface exposed to a plasma jet, Accepted on Plasma Sources Sci. Technol., (DOI: 10.1088/1361-6595/ab3c27).

Sobota, A., O. Guaitella, and E. Garcia-Caurel (2013), Experimentally obtained values of electric field of an atmospheric pressure plasma jet impinging on a dielectric surface, J. Phys. D: Appl. Phys. , 46(37), 372,001. 
Sobota, A., O. Guaitella, G. B. Sretenovic, V. V. Kovacevic, E. Slikboer, I. B. Krstic, B. M. Obradovic, and M. M. Kuraica (2019), Plasma-surface interaction: dielectric and metallic targets and their influence on the electric field profile in a khz ac-driven he plasma jet, Plasma Sources Sci. Technol., 28(045003).

Stollenwerk, L., J. G. Laven, and H.-G. Purwins (2007), Spatially resolved surfacecharge measurement in a planar dielectric-barrier discharge system, Physical Review Letters, 98 (255001).

Tschiersch, R., M. Bogaczyk, and H. E. Wagner (2014), Systematic investigation of the barrier discharge operation in helium, nitrogen, and mixtures: Discharge development, formation and decay of surface charges, J. Phys. D: Appl. Phys. , $47(36)$.

Viegas, P. (2018), Electric field characterization of atmospheric pressure helium plasma jets through numerical simulations and comparisons with experiments, Ph.D. thesis, École Polytechnique, France, http://www.theses.fr/2018SACLX061

Viegas, P., F. Pechereau, and A. Bourdon (2018a), Numerical study on the time evolutions of the electric field in helium plasma jets with positive and negative polarities, Plasma Sources Sci. Technol. , 27 (025007).

Viegas, P., E. Slikboer, A. Obrusník, Z. Bonaventura, A. Sobota, E. GarciaCaurel, O. Guaitella, and A. Bourdon (2018b), Investigation of a plasma-target interaction through electric field characterization examining surface and volume charge contributions: modeling and experiment, Plasma Sources Sci. Technol., $27(094003)$.

Wang, L., Y. Zheng, and S. Jia (2016), Numerical study of the interaction of a helium atmospheric pressure plasma jet with a dielectric material, Phys. Plasmas, 23(103504).

Weltmann, K.-D., and T. von Woedtke (2017), Plasma medicine - current state of research and medical application, Plasma Phys. Control. Fusion , 59(014031).

Wild, R., T. Gerling, R. Bussiahn, K.-D. Weltmann, and L. Stollenwerk (2014), Phaseresolved measurement of electric charge deposited by an atmospheric pressure plasma jet on a dielectric surface, J. Phys. D: Appl. Phys. , $47(042001)$.

Winter, J., R. Brandenburg, and K.-D. Weltmann (2015a), Atmospheric pressure plasma jets: an overview of devices and new directions, Plasma Sources Sci. Technol., $24(064001)$.

Winter, J., J. S. Sousa, N. Sadeghi, A. Schmidt-Bleker, S. Reuter, and V. Puech (2015b), The spatio-temporal distribution of $\mathrm{He}\left(2^{3} \mathrm{~S}_{1}\right)$ metastable atoms in a Mhzdriven helium plasma jet is influenced by the oxygen/nitrogen ratio of the surrounding atmosphere, Plasma Sources Sci. Technol. , 24 (025015).

Yan, W., and D. J. Economou (2016), Simulation of a non-equilibrium helium plasma bullet emerging into oxygen at high pressure (250-760 torr) and interacting with a substrate, J. Appl. Phys., 120(123304). 
Yue, Y., X. Pei, D. Gidon, F. Wu, S. Wu, and X. Lu (2018), Investigation of plasma dynamics and spatially varying $\mathrm{O}$ and $\mathrm{OH}$ concentrations in atmospheric pressure plasma jets impinging on glass, water and metal substrates, Plasma Sources Sci. Technol., $27(064001)$.

Zhang, Q., J. Zhuang, T. von Woedtke, J. F. Kolb, J. Zhang, J. Fang, and K.-D. Weltmann (2014), Synergistic antibacterial effects of treatments with low temperature plasma jet and pulsed electric fields, Appl. Phys. Lett., 105(104103).

Zheng, Y., L. Wang, and D. Wang (2018), Effect of oxygen as additive on an atmospheric nanosecond pulsed helium plasma jet impinging on a dielectric surface, J. Appl. Phys., 124 (123301).

Zhu, Y., T. Takada, and D. Tu (1995), An optical measurement technique for studying residual surface charge distribution, J. Phys. D: Appl. Phys. , 28, 1468-1477. 